NBER WORKING PAPER SERIES

\title{
BLOCKHOLDER IDENTITY EQUITY OWNERSHIP STRUCTURES, AND HOSTILE TAKEOVERS
}

\author{
Gary Gorton \\ Matthias Kahl \\ Working Paper 7123 \\ http://www.nber.org/papers/w7123 \\ NATIONAL BUREAU OF ECONOMIC RESEARCH \\ 1050 Massachusetts Avenue \\ Cambridge, MA 02138 \\ May 1999
}

The previous version of the paper was entitled "Rich Investors, Institutional Investors, and Dynamic Corporate Control". We are grateful to Bruce Greenwald, Lutz Hendricks, Cliff Holderness, George Mailath, Stephen Morris, Peter Norman, Walter Novaes, Sam Orez, Masako Ueda, S.Viswanathan, Andrew Winton, members of the Wharton Corporate Finance Discussion Group, and participants in seminars at Arizona State, Boston College, Columbia, McGill, the New York Federal Reserve Bank, Northwestern, and Utah for helpful discussions and comments. All remaining errors and shortcomings are solely our responsibility. The views expressed herein are those of the authors and do not necessarily reflect the views of the National Bureau of Economic Research.

1999 by Gary Gorton and Matthias Kahl. All rights reserved. Short sections of text, not to exceed two paragraphs, may be quoted without explicit permission provided that full credit, including ${ }^{\odot}$ notice, is given to the source. 
Blockholder Identity, Equity Ownership

Structures, and Hostile Takeovers

Gary Gorton and Matthias Kahl

NBER Working Paper No. 7123

May 1999

JEL No. G3

\section{ABSTRACT}

We determine firms' equity ownership structures and provide a theory of hostile takeovers by distinguishing the roles of two types of blockholders: rich investors and institutional investors. We also distinguish the roles of two types of stock markets: the block market and the market with small investors. Rich investors have their own money at stake while institutional investors are run by professional managers and hence face agency conflicts. Because rich investors face no agency problems they are better at monitoring managers. If their wealth is insufficient to control all corporations, then "agency-cost free" capital is scarce. We investigate the allocation of this scarce resource. A hostile takeover is the consequence of a state-contingent allocation of agency-cost free capital. We show that only rich investors engage in hostile takeovers. Institutional investors instead are either permanent blockholding monitors or facilitate takeovers by selling blocks to rich investors. Even though all firms are ex ante identical, some may rely on the takeover mechanism while others rely on permanent institutional monitoring. We characterize the ownership structure of firms showing, in particular, that (ex ante) identical firms can have different ownership structures. Some can have initially dispersed ownership while others have an institutional blockholder.

Gary Gorton

The Wharton School

University of Pennsylvania

Philadelphia, PA 19104-6367

and NBER

gorton@wharton.upenn.edu
Matthias Kahl

Anderson Graduate School of Management University of California, Los Angeles

110 Westwood Plaza

Los Angeles, CA 90095-1481

mkahl@anderson.ucla.edu 


\section{Introduction}

In this paper we address several important issues in corporate governance. What is the difference between the corporate governance roles of institutional investors and rich individuals? Why are takeovers such an important part of the monitoring regime in some capitalist economies (in particular, the U.S. and U.K.) even though they are associated with well-known inefficiencies (such as the free-rider problem)? Does institutional monitoring make the takeover market superfluous? Or is the takeover mechanism superior to permanent institutional blockholding? How can these two principal monitoring mechanisms coexist in some countries, such as the U.S. and U.K.? If blockholders are so important for monitoring, why do many firms have no large blockholder? Why do firms with concentrated and dispersed ownership coexist? And what is the role of the market in blocks of shares? We address these questions by investigating the implications of the agency problem at the root of corporate governance.

In governing corporations some investors have sufficiently large blocks of stock that agency problems associated with dispersed ownership of the corporation are alleviated. But blockholders themselves may face agency problems. For example, institutional investors are run by professional managers who may not make valuemaximizing decisions. A rich investor, however, has enough capital to take a controlling position without facing an agency problem himself in controlling the corporation. If these rich investors do not have enough such "agency cost-free" capital to control all corporations, then agency cost-free capital is a scarce resource. In this paper, we ask how scarce agency cost-free capital is allocated. Answering this question explains how the ownership structure of corporate assets is determined and provides a theory of hostile takeovers. A hostile takeover is the consequence of a state-contingent allocation of agency cost-free capital, as distinct from a buy-and-hold allocation. The analysis distinguishes the different roles of rich investors and institutional investors, shows that concentrated ownership and dispersed ownership can coexist (with identical firms), emphasizes the importance of block trades, and explains how different capitalist economies can have different equity ownership structures and different types of corporate control markets.

The notion of scarce "agency cost-free" capital which we pursue in this paper is implicit in Berle and Means (1932) who provide the central paradigm of corporate finance. 
They observe that the scale of modern technology makes corporations so large that they cannot all be owned, and hence controlled, by single families or rich individuals. ${ }^{1}$ Consequently, they argue, because the wealth of rich individuals or wealthy families is scarce, the ownership of corporate assets is dispersed and this empowers managers to act in their own interests rather than in the interests of shareholders. A difficulty with this argument is that the ownership structure of firms is endogenous (see Demsetz (1983)). ${ }^{2}$ Large block shareholders may alleviate some of the problems caused by the separation of ownership and control. ${ }^{3}$ Even without a large shareholder present, managers may be disciplined by the threat of disciplinary takeovers (see Jensen and Ruback (1983)).

These observations do not provide a coherent explanation for the ownership structures of public corporations. If blockholders can overcome the problem of the separation of ownership and control, then blockholders should always be present. This is possible if small investors can band together to form "institutional investors" or "financial intermediaries." Indeed, some have argued that institutional investors should play this role (e.g., Black (1992a,b), Coffee (1991), and Black and Coffee (1994)). But, their effectiveness is often questioned. Hostile takeovers might be effective in the absence of pervasive permanent blockholders. But, hostile takeovers are also puzzling. First, they only seem to occur in some capitalist economies. Second, hostile takeovers are inefficient due to the free-rider problem. Firms that rely on the takeover market for monitoring are restructured only when the benefits of restructuring are large enough to compensate the raider for sharing the surplus generated by his monitoring activity with the remaining, passive, investors. Hence, it seems that relying on permanent institutional blockholders is more efficient.

Our analysis proceeds by returning to the central assumption of the Berle and Means hypothesis, that the wealth of rich individuals is scarce. We focus on the identity of blockholders, arguing that institutions are different from rich investors with agency cost-

\footnotetext{
${ }^{1}$ La Porta, Lopez-de-Silanes, and Shleifer (1999) have recently questioned this paradigm, pointing out that in many countries the state and large families own many large firms.

${ }^{2}$ Indeed, Demsetz and Lehn (1985) find some evidence that block shareholders are more prevalent in firms where there is reason to believe that agency problems are more pronounced.

${ }^{3}$ See Berle and Means (1932), Demsetz and Lehn (1985), Shleifer and Vishny (1986), Kahn and Winton (1996) and Maug (1996), among others.
} 
free capital. ${ }^{4}$ In our analysis, rich investors with limited wealth face no agency problems in the deployment of their wealth. The "scarcity" of rich investors means that they cannot control all the corporations in the economy. Other, small, investors cannot synthetically replicate rich investors by forming coalitions because when they form an "institutional investor" or "financial intermediary" they cannot avoid agency problems. The reason is that institutions (e.g., financial intermediaries, pension funds, other money managers, the State, large extended families, and so on) are themselves run by professional managers. Rich investors are unique in having a limited amount of "agency cost-free" capital. Hence, they are better at monitoring managers than institutional investors.

We show that the corporate governance roles of rich investors and institutional investors are distinct. Rich investors may be either permanent blockholders or may engage in state-contingent monitoring via takeovers. In contrast, institutional investors never engage in takeovers. Nevertheless, they have important roles to play. While imperfect monitors due to agency problems, they can still monitor management to some extent as permanent blockholders. This is important because the rich investors have limited wealth. Institutional investors may also facilitate takeovers by transferring blocks to a rich investor engaging in a takeover. We show that the institutional block market is critical in determining how agency cost-free capital is allocated.

The special monitoring ability of rich investors and the scarcity of their wealth drives the difference in the governance roles of the two types of blockholders. In some states of the world monitoring is particularly valuable because the firm may need a restructuring that the manager does not want to implement. All investors would like to concentrate their blockholding on those states of the world but such state-contingent blockholding is costly due to the inefficiencies associated with the takeover market (in particular, the free-rider problem). This cost can be offset by the special monitoring ability of rich investors. Takeovers can lead to superior monitoring because the best monitors deploy their agency-cost free capital in the secondary stock market. Thus, takeovers can be an optimal monitoring mechanism despite the inefficiencies associated with buying the target firm's stock. Moreover, due to the scarcity of their wealth, rich

\footnotetext{
${ }^{4}$ Empirically, a number of researchers have examined the identity of blockholders and noted differences. Examples include Holderness and Sheehan (1985), Barclay and Holderness (1989, 1991), and Bethel, Liebeskind, and Opler (1998). We discuss the relevant empirical literature later in the paper.
} 
investors may acquire blocks only in those states of the world in which monitoring is needed most. Such a strategy of state-contingent blockholding corresponds to (hostile) takeovers. In contrast, institutional investors do not engage in takeovers. Were institutional investors to engage in costly takeovers, they would be unable to profitably buy controlling blocks in targets because they are not scarce and hence behave competitively. They would earn zero profits and hence not be able to cover the costs of mounting a takeover.

Equity ownership structures vary across the world's economies (see La Porta, Lopez-de-Silanes and Shleifer (1999)). For example, Germany contrasts with the U.S. and U.K. In Germany 85 percent of the largest companies have a single shareholder owning more than 25 percent of the voting shares (see Franks and Mayer (1998) and Gorton and Schmid (1998)). ${ }^{5}$ Consistent with this observation, a number of equity ownership structures can occur in the equilibrium of the model even though firms are identical ex ante. One parameter region gives rise to an equilibrium that looks to some extent like Germany. All firms have a permanent blockholder and there are no hostile takeovers. However, in accordance with the findings by Franks and Mayer (1998), there can be an active block market that may be a substitute for takeovers. Another parameter region gives rise to an equilibrium that looks more like the U.S. and U.K. While some firms may have an institutional blockholder, there are also firms without large blockholders. The takeover market is active and dominated by rich individuals. In the model, we determine the fraction of firms with initially dispersed and with initially concentrated ownership. Coexistence of dispersed and concentrated ownership occurs when some firms rely on permanent institutional blockholders to monitor while others rely on takeovers. In this case, the more firms rely on the takeover market for monitoring, the worse off each of them is. This is because they have to share the scarce monitoring resources of the rich investors. Hence, they are taken over only with a certain

5 In the U.S. a survey of stock exchange listed firms in 1984 showed that only 20 percent of the firms had at least one nonofficer who owned ten percent of firm stock; thirteen percent of the firms were majority owned (see Holderness and Sheehan (1988)). This includes firms listed on the New York Stock Exchange, the American Stock Exchange and over-the-counter firms; a total of 5,240 firms. In the U.K the proportion of public limited companies with a majority shareholder is also far smaller than in Germany (see Edwards and Fischer (1994)). 
probability (determined endogenously in the model). The fraction of firms relying on the takeover market adjusts so that all firms are indifferent between both monitoring mechanisms.

Our paper is related to a number of other papers. Bolton and von Thadden (1998) argue that there is a trade-off between monitoring quality (which is better when the firm has a permanent blockholder) and investors' liquidity demand (having a permanent blockholder reduces liquidity). The takeover market is active due to investors' liquidity demand. ${ }^{6}$ In contrast to Bolton and von Thadden, takeovers arise in our setting despite their inefficiencies due to the superior monitoring ability of rich investors. Bolton and von Thadden do not distinguish between different kind of blockholders, the focus of our paper. Aghion and Bolton (1992) provide a model of state-contingent corporate control in which poor performance leads to control by debt holders (see also Dewatripont and Tirole (1994)). Their model is one of a closely held firm and debt holders are assumed to face no agency conflicts themselves. Diamond (1984) develops a model in which a large investor can be synthetically created by many small investors, who can form a coalition (a financial intermediary). In contrast, we assume that such synthetic large investors cannot perfectly replicate a single rich individual. ${ }^{7}$

Some papers (mainly in the law literature) discuss differences between institutional investors and rich investors. For instance, the agency problems and conflicts of interests that may hamper the monitoring ability of institutional investors are discussed in Black (1992a, 1992b), Coffee (1991), and Black and Coffee (1994) (for empirical evidence on conflicts of interest, see Brickley, Lease, and Smith (1988)). These papers do not explore the consequences of this agency problem within the institutional investors. There is some empirical evidence that suggests that there is indeed a difference in the monitoring abilities of institutions and individuals. This literature is discussed in Section II.

The remainder of the paper is structured as follows. In Section II, we present the

\footnotetext{
${ }^{6}$ Black (1992a, p. 875) argues that it may be difficult to explain the lack of blockholding by financial intermediaries with a liquidity preference argument. He argues that one major reason for the existence of financial intermediaries is liquidity transformation.

${ }^{7}$ Kahn and Winton (1998) also analyze the role of blockholders in monitoring. They discuss the potential conflict between gathering information for two purposes: to trade on this information or to implement a restructuring. Admati, Pfleiderer, and Zechner (1994) analyze the trade-off between risk-sharing and optimal monitoring and the resulting asset allocation of a large investor and many small investors. None of these papers, however, distinguishes between institutional investors and rich investors.
} 
model. Section III analyzes the model and characterizes the optimal investment strategies of the rich investor and the institutional investors. Section IV determines the equilibrium firm ownership structures at date 0 . Section $\mathrm{V}$ analyzes the model under an alternative informational assumption that allows the market for block trades between the institutional investors and the rich investor to be active. Section VI concludes.

\section{The Model}

We begin with an overview of the model, then provide the details, and finally, discuss some of the important assumptions.

\section{A. Overview}

There are three dates in the model economy: 0, 1, and 2. All agents are risk neutral and utility of consumption is defined over date 2 payoffs. At date 0 , a continuum of identical entrepreneurs with total measure one seek to finance their projects. The representative firm is run by a manager and finances its project exclusively with equity. There are two types of potential investors. There is a continuum of small investors and there is a single Rich Investor (that is, an investor with measurable wealth). It takes many small investors to finance the project of any one firm, but the Rich Investor has enough wealth to finance a strictly positive measure of firms. Small investors can invest as individuals or they can pool their wealth into funds, which we shall call institutional investors. An institutional investor is an intermediary that is overseen by a manager. ${ }^{8}$

At date 1 a public signal arrives concerning each firm: there is either good news or bad news about the firm's final date 2 payoff. Bad news means that the date 2 payoff will be low unless the firm is restructured. "Restructuring" means taking actions that might

\footnotetext{
${ }^{8}$ We model the two extreme types of monitors: "funds" with many small investors run by a manager who presumably has a lot of discretion and rich investors without any agency problems. In reality, there are also entities that fall somewhere in between these two extremes. For instance, hedge funds have a limited number of rich individuals. Until recently, hedge funds were limited to no more than 100 investors each with at least $\$ 200,000$ in income for the previous two years and a net worth of at least $\$ 1$ million. In 1996 the law changed to allow up to 500 investors provided each has an investment portfolio valued at $\$ 5$ million or more. While it is an empirical matter, we view some hedge funds controlled by a few rich investors as corresponding to our "Rich Investor." Similarly, blocks held by families could reasonably be viewed as constituting a "Rich Investor," unless the family is a large, extended, family, in which case it might be viewed as an "institutional investor." That is, a large family must delegate management of the family's holdings to one family member, who then acts as manager. Ownership by the State would seem to fall into the category of "institutional investor."
} 
improve the firm's date 2 payoff. Depending on the likelihood that the restructuring will be successful, it may or may not be optimal to restructure the operations of a firm that has received bad news. There are two problems in restructuring. First, managers never voluntarily restructure their firms; only blockholders can restructure. Second, assessing the desirability of a restructuring requires expending resources to produce information about the likelihood of the success of a restructuring.

In producing information about the likelihood of restructuring success of firms that have received bad news, there is an important difference between an institutional investor and the Rich Investor. The agency problem with the institutional investor is taken to mean that the chance of learning the restructuring success likelihood is lower for the institutional investor than for the Rich Investor (since the Rich Investor, by definition, faces no agency problem). Following any information production about restructuring success, trading in the stock market occurs. ${ }^{9}$ In the stock market institutional investors and the Rich Investor may acquire a block of a firm's shares in order to implement a restructuring.

At date 2 firms with blockholders desiring to restructure are restructured followed by the realization of final payoffs. Figure 1 shows the sequence of events.

\section{B. Detailed Assumptions}

Each entrepreneur has a business idea, but needs to obtain financing (in the amount $I$ ) and a professional manager to run the firm (though this is not explicitly modeled). While managers run the firm after date 0 , entrepreneurs make the initial decision about the source of financing. All firms are financed exclusively with equity. Entrepreneurs auction off the equity with a second price auction in which it is purchased by small individual investors or blocks are purchased by institutional investors or the Rich Investor. While all firms are identical ex ante, after selling their equity their publicly observed equity ownership structures may differ, as will be seen.

Payoffs on the project occur at date 2. Payoffs depend on whether the firm is in the good state (receives good news) or in the bad state (receives bad news) at date 1 and on whether the firm is restructured (if it is in the bad state). The state is publicly observable. The probability of receiving bad news at date 1 is $\delta$ (with probability $1-\delta$ good news is

\footnotetext{
${ }^{9}$ As will be seen, in the block market the block trades occur prior to any information production.
} 
received). ${ }^{10}$ A firm that receives bad news will be called "distressed." ${ }^{11}$ Date 2 payoffs are as follows:

A1. Project Payoffs. Firms that received good news at date 1 receive $R$ at date 2 for sure. It is never optimal to restructure these good firms. Distressed firms will have a date 2 payoff of $L_{2}>0$ if they are not restructured. If a distressed firm is restructured, its date 2 payoff is $H(\beta)>0$ with probability $\rho$ and zero with probability $1-\rho$, where $\beta$ is the fraction of the firm's equity owned by the blockholder.

Blockholders may be useful because:

A2. Entrenched Management and Blockholders. Managers never voluntarily restructure their firms. Furthermore, a block shareholder is necessary to implement a restructuring because small investors cannot coordinate (due to free-rider problems).

The Rich Investor may be the blockholder or, as discussed below, small investors can pool their funds, to create an institutional investor, in an attempt to mimic the Rich Investor.

The prospects of a distressed firm when it is restructured are captured by the parameter $\rho$. This probability is not known by any agent at date 0 . We assume:

A3. Restructuring Success Likelihood. It is common knowledge that $\rho$ is uniformly distributed on $[0,1]$.

\footnotetext{
${ }^{10}$ In the following, probabilities such as $\delta$ are treated both as a probability for an event to happen to an individual firm and the fraction of firms at date 1 that actually experience this event. Of course, with a continuum of firms, there are some well-known technical problems with an appeal to a law of large numbers. For a discussion of these problems and solutions to them, see Judd (1985) and Feldman and Gilles (1985).

${ }^{11}$ It should be noted that the important point about the "distressed" state is that agency conflicts are severe in this state of the world: the manager is reluctant to implement a restructuring even if it would be value increasing. The "bad news" state could describe a number of different situations. For example, it could be interpreted as a firm in a mature industry that has excess cash that management is unwilling to pay out to shareholders and instead is inclined to invest in negative NPV projects (see Jensen (1986)). We use the term "distress" only for convenience and do not mean to imply that our analysis is restricted to economically distressed firms.
} 
Note that restructuring may increase the expected value of a distressed firm, but it may also lower it below what the current managerial strategy can achieve, namely, $L_{2}$. Thus not all firms that receive bad news will do worse under the strategy of incumbent management than under a restructuring.

As will be discussed below, institutional investors and the Rich Investor may attempt to learn $\rho$ and hence the desirability of a restructuring. If they do not generate new information about the firm's prospects, they will not restructure the firm:

A4. Value of Information Production. Given the prior belief about $\rho$, no restructuring is the best response: $0.5 H(\beta)<L_{2}$ for all $\beta$, where $\beta$ denotes the fraction of equity owned by the blockholder

At date 1 shares of all firms may be traded; the Rich Investor or an institutional investor can acquire a block of a firm's equity from either an institutional investor (in the block market) or from many small investors. For simplicity we do not endogenize the size of the block an investor can acquire at date 1 if he buys from many small investors; instead we assume that either a fraction $\lambda$ can be purchased or no block at all (see A7). ${ }^{12} \mathrm{We}$ assume that $\lambda$ is sufficiently large for the holder of that fraction to implement the restructuring. The size of blocks is important because restructuring outcomes are affected by the concentration of ownership at date 2; outcomes are increasing in the blockholder's ownership fraction. In particular, a larger block gives the investor more incentives and more power to force the firm to make more efficient decisions. This is formalized in:

A5. Effects of Block Size. $\partial H / \partial \beta>0$ and $L_{2}<H(\lambda)<H(1) \equiv H<R$.

Assumption A5 says that firm value, given a restructuring, is always increasing in block size. This assumption is stronger than we need and is made to simplify the analysis. It

\footnotetext{
${ }^{12}$ In the liquidity-trading framework presented in Appendix B the fraction of the firm that the Rich Investor can buy without fully revealing his private information is determined by the fraction of early consumers.
} 
guarantees that if the large investor or an institutional investor acquires a block at date 0 , then the entire equity is acquired, simplifying the date 0 ownership structure. ${ }^{13}$

The Rich Investor has sufficient resources to purchase blocks of shares, but small investors individually cannot buy blocks. Small investors, however, can attempt to synthetically create a large investor by forming a fund or institutional investor. A manager (who is not explicitly modeled) runs each institutional investor. This leads to an agency conflict within the institutional investor. For simplicity we do not model the effort choice of the institutional investor's manager, i.e., the standard principal-agent conflict, explicitly. Instead, we assume that as a result of the principal-agent conflict, the manager of the institutional investor is worse at producing information about a firm's prospects than the Rich Investor: ${ }^{14}$

A6. Agency Costs in Institutional Investors. If the manager of an institutional investor investigates a distressed firm's prospects, he learns $\rho$ with probability $\pi_{L}$. If the Rich Investor investigates the prospects of a firm, he learns $\rho$ with probability $\pi>\pi_{L}$.

Investigation of distressed firms is costly; it costs $c$ to investigate a measure one of firms. In order to assure that investigation pays, we assume $\pi_{L}\left(\int_{\rho^{+}}^{1}\left(\rho H-L_{2}\right) d \rho\right)>c$, where $\rho^{+}=\frac{L_{2}}{H}$ and is discussed below. For simplicity, we assume that if one blockholder has investigated the firm and has not learned $\rho$, then any other investigation by a different blockholder will also not reveal $\rho$. Moreover if one institutional blockholder's investigation has revealed a particular value of $\rho$, then an additional investigation by a different institutional blockholder will lead this blockholder to learn the same value of $\rho$.

The equilibrium strategies of the small investors and the Rich Investor will depend on the price formation mechanism for the date 1 stock price. But the results of the analysis, below, do not depend on the details of the price formation in the date 1 stock market. All

\footnotetext{
${ }^{13}$ Zwiebel (1995) provides an analysis of the benefits of partial blockholding and coalitions among several blockholders.

${ }^{14}$ The result that we rely on is the basic outcome of the principal-agent model, namely, that the effort choice of the manager/agent is suboptimal relative to the first-best effort choice which would be made were there no agency problem.
} 
that the analysis requires is that prices do not fully reflect the improvement in firm value that is brought about by the Rich Investor's restructuring activity, that is, the GrossmanHart (1980) free-rider problem is not fully present. In Appendix B a model of price formation at date 1 is presented that is consistent with the analysis in the main text. To be consistent with that model we make the following two assumptions:

A7. Liquidity Trade. At date 1, fraction $\lambda$ of the small investors sell the shares of any distressed firm; the remainder hold their shares until date 2.

A8. The Date 1 Stock Price of Distressed Firms. Let $P$ be the price of a distressed firm's equity in the date 1 stock market. It is assumed that $P \geq L_{2}$ and that $\frac{\partial P}{\partial \delta}=0$.

The assumption that $P \geq L_{2}$ seems natural and should be the result of any reasonable price formation mechanism. A blockholder will buy shares at date 1 to implement a restructuring of the firm only if the expected value of the firm under a restructuring is no less than the value of the firm under the current managerial strategy, $L_{2}$. Hence, the value of the firm is at least $L_{2}$, and nobody would sell shares at a price below $L_{2}$. We will see that the assumption holds in the equilibrium in our price formation mechanism presented in Appendix B. A8 also says that the date 1 equity value does not depend on $\delta$. Again, we will verify that this holds in the most important parameter regions in the model of Appendix B.

At date 1 the Rich Investor may choose to invest by first investigating some distressed firms and then choosing those in which to acquire a block position. There is only one round of investigation, and hence the search is not sequential. This specification of the Rich Investor's problem is not essential for our results.

We assume that small investors are competitive whether they act as individuals or form funds (institutional investors). ${ }^{15}$ Hence, at date 0 shares are priced such that individual small investors and institutional investors make zero profits. However, if the Rich Investor supplies funds by himself, he can extract the difference between the equity

\footnotetext{
${ }^{15}$ The model does not determine the size of the institutional investors. However, we assume that if small investors form funds, then there are many such institutional investors that are competing with each other.
} 
value of the firm that obtains funds from him and the equity value of a firm that obtains funds from an institutional investor. This extreme assumption on the bargaining power of the Rich Investor simplifies the analysis but could be relaxed without changing the qualitative results of the analysis.

We assume that there is only one round of trading at date 1. It is impossible to sell some shares and then acquire other shares at date 1. This assumption makes the distinction between taking a position at date 0 and taking a position at date 1 meaningful. It ensures that buying shares at date 0 and then selling shares of firms receiving good news in order to acquire shares of firms receiving bad news (because they may need a restructuring) is not a dominant strategy for the Rich Investor. Hence, there is a cost to taking a position at date 0 . This assumption is discussed in more detail below.

\section{Discussion of Assumptions}

We focus on two differences between the Rich Investor and the synthetic large investors created by the small investors, the "institutional investors." First, the Rich Investor is scarce. In contrast, small investors and their institutional investors are competitive. This means that the Rich Investor has some bargaining power. If the Rich Investor buys blocks of shares at date 0 , he can extract surplus from his potential future restructuring services. If he buys a block at date 1 , he may be able to extract surplus at that date as well. Small investors and their institutional investors compete for shares at date 0 . At date 1, if an institutional investor investigates a distressed firm, then there are always at least two institutional investors doing the investigation.

The second difference is that rich investors are better monitors than institutional investors. This assumption is consistent with Holderness and Sheehan (1985) who find that the abnormal returns associated with the acquisition of a stake of a company's stock by six of the most well known and active "raiders" (Charles Bluhdorn, Carl Icahn, Irwin L. Jacobs, Carl Lindner, David Murdock, Victor Posner) are significantly higher than those associated with the acquisition of stakes by other investors. Also, Boehmer (1998) shows that in Germany, the abnormal returns for firms that make acquisitions is higher when they have a large blockholder holding between 25 and 50\% of the firm's shares. Interestingly, the identity of the blockholder matters for the abnormal returns. Firms that have families 
as blockholders do better acquisitions than firms that have an institutional blockholder such as a bank. This suggests that rich investors are better at monitoring management than institutions. Finally, Carleton, Nelson, and Weisbach (1998) describe monitoring activity of one of the most important active institutions (TIAA-CREF) and conclude that it is not nearly as consequential as the restructuring imposed by raiders in the takeover market.

The model assumes that agency problems in firms are not always present to the same degree. Rather, there are certain states of the world where these problems are more severe. In the model these states of the world correspond to states in which bad news arrives, states which we have called "distress." Clearly, if the costs of agency problems in firms were constant across all states of the world, then there would be no issue of state contingent allocation of the Rich Investor's "agency cost free capital."

At date 2, the firm may be restructured. Restructuring may take the form of asset sales, a divestiture of a business line, or a change in business strategy. We assume that incumbent managers are averse to restructuring. One rationale for this is that these managers want to preserve projects that provide private benefits to them ("pet projects") which may also help to entrench themselves (see Shleifer and Vishny (1989)). Alternatively, managers may be concerned about the inferences that the labor market draws from the restructuring decisions: because firms in bad shape are more likely to need a restructuring, implementing a restructuring may convey negative news about the current situation of the firm. Incumbent management can be held responsible for the troubled situation of the firm by the outside labor market. ${ }^{16}$ Clearly we implicitly have to assume that contracts cannot fully alleviate managerial restructuring aversion.

Acquiring blocks at date 0 would be a dominant strategy for the Rich Investor if he could sell the shares of firms that turn out not to be distressed at date 1 (so that his restructuring activity is not needed), and instead acquire blocks in distressed firms. Our assumption that there is only one round of trading rules out this strategy. This assumption serves the sole purpose of capturing in a very simple way that the opportunity cost of acquiring blocks before the realization of the state is that this reduces the amount of money that can be invested in blocks of firms that have realized their state. Without the

\footnotetext{
${ }^{16}$ For a career concern model formalizing this idea in the context of an aversion to divest see Boot (1992)). Indeed, Weisbach (1994) finds that while incumbent managers are averse to divestitures, new management often implements such divestitures.
} 
assumption of one round of trading only, there would be no opportunity cost to acquiring blocks at date 0 because, to make our model tractable, there are no distressed firms one could invest in at date 0 . An alternative but much more cumbersome way to capture this opportunity cost of acquiring blocks before the realization of the state would be an overlapping generation model in which at all times firms with their state realized and firms in which the state is not yet realized would coexist. In such a more realistic model, our assumption of only one trading round would not be needed. Investing in blocks before the realization of the state would clearly come at the cost of not being able to invest the same money in blocks of firms for which the state has been realized. Hence, our assumption captures in a reduced form nothing else than that the same dollar cannot be spent twice.

\section{The Allocation of Agency-Cost Free Capital: No Active Date 1 Block Market}

Institutional investors may acquire blocks of shares in firms at date 0 . If they do, then at date 1, when some of those firms are distressed, they may investigate and restructure some of them or they may transfer their blocks to the Rich Investor, who is more efficient at the task of investigation. We begin the analysis with the case where there is no active date 1 block market, i.e., institutions do not transfer blocks to the Rich Investor at date 1. Below we will make an assumption under which this market will not be active.

The problem then is as follows. The Rich Investor and the small investors can acquire block positions in firms at date 0 or date 1 . Small investors cannot acquire blocks individually, but may choose to form institutional investors that can acquire blocks. Small investors and the Rich Investor choose their strategies to maximize their respective utilities, taking the strategy of the other as given and taking the price of distressed firms' shares at date 1 as given. We solve the model by backwards induction. First, we analyze the restructuring policies implemented at date 2. Initially, we consider the restructuring policies by investors who have acquired blocks at date 0 ("date 0 blockholders"). We then show that institutional investors will always buy blocks at date 0 and never at date 1 . Then we turn to the restructuring policy of the Rich Investor under the assumption that he buys blocks in the date 1 stock market. Next we characterize the conditions under which the Rich Investor will buy blocks at date 1 and the conditions under which he will buy blocks 
at date 0 . Finally, we will analyze the whole game and determine the date 0 equity ownership structures.

\section{A. Restructuring by Date 0 Blockholders}

First, we analyze the conditions under which the firm will be restructured if a blockholder has become informed about the distressed firm's prospects. We begin with the restructuring decision of blockholders (whether the Rich Investor or an institutional investor) who acquired a block at date 0 . Lemma 1 is straightforward and characterizes the restructuring policy of a date 0 blockholder who learns $\rho$. We assume that the blockholder restructures if he is indifferent between restructuring and not restructuring.

Lemma 1: A date 0 blockholder who owns a block of fraction $\theta$, and who learns $\rho$, restructures if and only if $\rho H(\theta) \geq L_{2}$ or, equivalently, $\rho \geq \frac{L_{2}}{H(\theta)} \equiv \rho^{+}(\theta)$.

Proof: See Appendix A.

Lemma 2, emanating from A5, simplifies the analysis as it guarantees that, if there is a blockholder, there is only one blockholder in a firm.

Lemma 2: A date 0 blockholder will acquire 100\% blocks. He restructures if and only if

$$
\rho \geq \frac{L_{2}}{H(1)} \equiv \frac{L_{2}}{H} \equiv \rho^{+}(1) \equiv \rho^{+} .
$$

\section{Proof: See Appendix A.}

Note that these two lemmas imply that a date 0 blockholder (if he has learned $\rho$ ) will always implement the socially optimal restructuring decision because the date 0 blockholder becomes the firm's residual claimant (actually, he becomes its sole owner). Restructuring decisions, however, are not in general first-best because the blockholder, whether the Rich Investor or an institutional investor, may not learn $\rho$. 
Because of the agency problem, the institutional investor is not as efficient as the Rich Investor in learning $\rho$. The Rich Investor learns $\rho$ with probability $\pi$ while the institutional investor learns $\rho$ with probability $\pi_{L}\left(\pi>\pi_{L}\right)$. Because small investors are competitive while there is only one Rich Investor who is assumed to have all the bargaining power, the Rich Investor is able to appropriate all the surplus generated by the improvement in restructuring decisions brought about by his superior monitoring ability. This implies:

Lemma 3: The Rich Investor's profit from investing all his wealth at date 0 is $\frac{W}{(1-\delta) R+\delta\left[L_{2}+\pi_{L} \int_{\rho^{+}}^{1}\left(\rho H-L_{2}\right) d \rho\right]} \delta\left(\pi-\pi_{L}\right) \int_{\rho^{+}}^{1}\left(\rho H-L_{2}\right) d \rho$.

Proof: See Appendix A.

The Rich Investor's profit is the gain in firm value due to the difference in his ability to produce information relative to the ability of the institutional investor to produce information, $\pi-\pi_{L}$. This is positive.

\section{B. Trading Activity at Date 1}

So far, the Rich Investor was assumed not to invest at date 1. Instead, he exhausted his wealth purchasing blocks of shares at date 0 . In that case, firms that obtain funds from many small investors at date 0 are never restructured later, regardless of $\rho$, unless institutional investors purchase blocks in the date 1 market. Even if institutional investors are not as efficient at producing information as the Rich Investor, i.e., $\pi_{L}<\pi$, it is feasible for institutional investors to buy blocks at date 1 in order to restructure firms. Proposition 1 shows that they will not do so.

Proposition 1: Institutional investors do not acquire blocks at date 1.

Proof: See Appendix A. 
Institutional investors monitor in the sense of restructuring firms in which they already own blocks, but they do not engage in takeovers, that is, the date 1 acquisition of block positions made to restructure firms. The reason for this is that since institutional investors are not scarce, they compete away any profits they might have earned from acquiring blocks at date 1 and hence can not recover the investigation costs.

The Rich Investor may buy a block from many small investors at date 1 or from an institutional investor. Whether the market for block transfers from institutional investors to the Rich Investor is active depends on the informational structure of this market. In this section we assume:

A10. Information Production Not Observable: It is not observable whether an investor has investigated a firm or not.

This assumption implies that the market for block transfers from institutional investors to the Rich Investor at date 1 is not active:

Lemma 4: If A10 holds, then the Rich Investor never buys a block from an institutional investor at date 1.

\section{Proof: See Appendix A.}

Essentially, the market breaks down due to an informational problem similar to Akerlof's (1970) lemons' problem. The only reason for a trade between the institutional investor and the Rich Investor is the superior ability of the Rich Investor in investigating distressed firms. A profitable trade could occur only before either side has investigated the firm. However, the Rich Investor is better off secretly investigating firms and then making offers only for the firms that are good enough to be restructured, acquiring them at the "average" price for all distressed firms and hence buying them at a discount at the expense of the institutional investor. By A10, there is no way for the institutional investor to know that the Rich Investor has not investigated, and hence this problem cannot be avoided. 
Alternatively, there might be trade if one of the trading partners or both investigate the firms before trading. But in this case there is no gain from trade since the comparative advantage of the Rich Investor is in investigating, not in restructuring once $\rho$ has been learned. The only way for the Rich Investor to benefit from trade then is at the expense of the institutional investor. Hence there is no active block market.

The following Lemma further characterizes trade at date 1 and simplifies the subsequent analysis:

Lemma 5: No date 0 blockholder sells shares of a firm at date 1.

Proof: See Appendix A.

The reason is as follows. By Proposition 1, institutional investors do not acquire blocks at date 1, and by Lemma 4 the Rich Investor never acquires blocks from an institutional investor. Therefore, the only buyers would be small investors and they cannot restructure firms. So, a firm sold at date 1 is known to be worth $L_{2}$. Selling it is not profitable because the blockholder can achieve this payoff by keeping the firm and not restructuring it.

\section{The Rich Investor's Behavior at Date 1 If He Does Not Become A Date 0 Blockholder}

We now turn to the case where the Rich Investor acquires blocks at date 1. In what follows, we temporarily assume that he spends all his wealth on acquiring blocks at date 1 . Below we will characterize when that is his optimal strategy. If the Rich Investor acquires a block of shares of a distressed firm at date 1, then this firm can be restructured. If the Rich Investor does not learn $\rho$, he anticipates that he will not restructure, by A4, and hence he does not acquire a block in this firm. If he expends resources to learn $\rho$, he may acquire a block of shares in a distressed firm if he learns $\rho$.

By Lemma 4 the Rich Investor does not buy blocks at date 1 from institutional investors. If he is to buy blocks at date 1 , he must purchase blocks of size $\lambda$ from small 
investors. Assuming the Rich Investor learns $\rho$, when will he choose to enter the date 1 stock market and buy a block of size $\lambda$ ? The Rich Investor must choose a measure of distressed firms to investigate, $\mu$, and, from among those firms for which the Rich Investor learns $\rho$, he must choose a subset of firms in which to buy a block of size $\lambda$. That is, knowing $\rho$, the Rich Investor must choose a cut-off value for $\rho$, say $\bar{\rho}$, such that he buys a block if $\rho \geq \bar{\rho}$. The Rich Investor's problem is to choose $\mu$ and $\bar{\rho}$ to maximize:

$$
\mu\left(\pi \int_{\bar{\rho}}^{1}(\rho H(\lambda)-P) \lambda d \rho-c\right) \text { subject to: } W=\mu c+P \lambda \mu \pi(1-\bar{\rho}) .
$$

The budget constraint says that the Rich Investor's wealth is exhausted by investigation costs and the costs of buying blocks of shares. If the Rich Investor investigates measure $\mu$ of the distressed firms, the cost is $\mu \mathrm{c}$. Of the measure, $\mu$, he learns the quality $(\rho)$ for only a subset, measure $\pi$ of those investigated. Of these he only purchases blocks of those with $\rho \geq \bar{\rho}$, i.e., measure $1-\bar{\rho}$. He pays $P \lambda$ since he buys a fraction $\lambda$ and the entire equity value is $P$. Eliminating $\mu$ using the budget constraint, the Rich Investor's problem is to choose $\bar{\rho}$ to maximize:

$$
\left(\frac{W}{\pi(1-\bar{\rho}) P \lambda+c}\right)\left(\pi \int_{\bar{\rho}}^{1}(\rho H(\lambda)-P) \lambda d \rho-c\right) .
$$

The first term in brackets is the measure of distressed firms that the Rich Investor (with wealth $W$ ) can investigate if his policy is to buy a block of size $\lambda$ if and only if $\rho \geq \bar{\rho}$. Obviously, this is increasing if he buys a smaller set of firms, i.e., $\bar{\rho}$ is higher. Within the sample of firms receiving bad news that the Rich Investor investigates, he does not learn the realization of $\rho$ with probability $1-\pi$ (i.e., for this fraction of the distressed firms he learns nothing). Then he does not buy blocks in these firms because he would not restructure them (by A4) and because, by assumption, $P \geq L_{2}$. The second term in brackets describes the Rich Investor's payoff when he learns the realization of $\rho$ (this 
occurs with probability $\pi$ ) and then pays $P$ to buy blocks of size $\lambda$ if $\rho \geq \bar{\rho}$. The cut-off $\bar{\rho}$ determines the quality of the distressed firms that the Rich Investor will buy.

Let $\tilde{\rho}$ be the optimal choice of $\bar{\rho} .^{17}$ The cut-off firm quality $\tilde{\rho}$ depends on $c, \pi, H(\lambda)$, and $\lambda$, the variables in the Rich Investor's optimization problem described above. Note that it does not depend on $\delta$ since $\delta$ does not appear in the objective function directly and, by A8, also not indirectly through the date 1 price $P$. Proposition 2 characterizes the Rich Investor's trading and restructuring policy. It is assumed that the measure of firms without a date 0 blockholder is large enough to ensure that the Rich Investor cannot investigate and potentially acquire all firms that receive bad news at date 1. In the following, we will denote the fraction of firms that the Rich Investor investigates, $\left(\frac{W}{\pi(1-\tilde{\rho}) P \lambda+c}\right)$, by the symbol $\tilde{\mu}$.

Proposition 2: (Optimal Rich Investor Restructuring Policy) Suppose that the Rich

Investor invests all his wealth at date 1. Then, the Rich Investor buys a fraction $\lambda$ of a distressed firm and restructures the firm if and only if he learns that

$$
\begin{array}{r}
\rho \geq \tilde{\rho}(c, \pi, H(\lambda), \lambda) \text { where: } \tilde{\rho} \geq \frac{P(c, \pi, H(\lambda), \lambda)}{H(\lambda)} \text { and } \tilde{\rho}>\rho^{+} \text {if } \lambda<1 \text { or } P>{ }_{2} . \\
\frac{1}{\delta}\left(\frac{W}{\pi\left(1 \frac{\tilde{\rho}) P \lambda+c}{)}\right)}=\frac{\tilde{\mu}}{\delta}\right. \text { of all dis }
\end{array}
$$

firms.

\section{Proof:}

The Rich Investor's activity at date 1 improves the efficiency of the restructuring $\mathrm{d}$ cisions. In the absence of the Rich Investor no firm that has no date 0 blockholder would be restructured. The Rich Inves some of these firms that should be re indeed restructured, alleviating the problem of insufficient restructuring. However,

\footnotetext{
${ }^{17} \mathrm{We}$ assume that $\tilde{\rho}$ is unique.
} 
Proposition 2 also shows an inefficiency in the restructuring policies of firms that have no date 0 blockholder but an initially dispersed ownership.

To understand Proposition 2 recall that the socially optimal restructuring policy is to restructure firms with quality $\rho \geq \rho^{+}$. But, according to the proposition, $\tilde{\rho}>\rho^{+}$if $\lambda<1$ or $P>L_{2}$. Hence the Rich Investor when becoming active at date 1 , unlike a date 0 blockholder, may not restructure all firms that should be restructured from a social planner's perspective even if he knows the realization of $\rho$. This result is due to several inefficiencies in the restructuring policies of the Rich Investor at date 1.

The first inefficiency emanates from the fact that the Rich Investor may not have the ability to acquire all the shares of a distressed firm. To isolate this inefficiency, assume $P=L_{2}$, i.e., his policy is not affected by having to share some of the surplus from his restructuring activity with investors from whom he buys the shares. Then the Rich Investor will buy shares of distressed firms only if $\rho H(\lambda) \geq L_{2}$, or equivalently, only if $\rho \geq \frac{L_{2}}{H(\lambda)}$. Now, if $\lambda<1$, then, by A5, $\frac{L_{2}}{H(\lambda)}>\frac{L_{2}}{H} \equiv \rho^{+}$. Hence, this inefficiency in the restructuring policy at date 1 arises because the Rich Investor can only buy a limited block of shares at date 1 , which reduces his effectiveness at improving firm value. The fraction $\lambda$ depends on the liquidity of the date 1 security market (see Appendix B).

The second source of inefficiency arises from the fact that the Rich Investor may have to buy shares at a price higher than their value in the absence of a restructuring, sharing the surplus from his restructuring activity with existing equity holders (i.e., $P>L_{2}$ ). This may be the case because sellers of shares and the Rich Investor split the surplus generated by the Rich Investor's restructuring activity in bargaining or because the price reflects the possibility that the Rich Investor will buy a block and restructure the firm. The model of price formation presented in Appendix B formalizes the latter idea. This second inefficiency can best be seen if one abstracts from the first inefficiency by assuming $\lambda=1$ and hence $H(\lambda)=H(1) \equiv H$. Suppose $P>L_{2}$. Then, the Rich Investor will buy shares in a distressed firm only if $\rho \geq \frac{P}{H}>\frac{L_{2}}{H} \equiv \rho^{+}$. 
The third inefficiency in the restructuring policies of firms without a date 0 blockholder stems directly from the Rich Investor's limited wealth. He may not be able to investigate all firms receiving bad news. This leads to a lack of restructuring of those firms which are not investigated by the Rich Investor, but which have $\rho \geq \rho^{+}$. ${ }^{18}$

Despite these inefficiencies in the restructuring policies of firms without a date 0 blockholder, their restructuring policies may be more efficient than the restructuring policies of firms that have a date 0 blockholder if the Rich Investor is active in the date 1 stock market because $\pi>\pi_{L}$. But under what circumstances will the Rich Investor be active in the date 1 stock market? This question is addressed in the next subsection.

\section{The Rich Investor's Choice: Blockholding at Date 0 or Date 1?}

How will the Rich Investor allocate his wealth: acquiring blocks at date 0 or date 1 ? Proposition 3 gives the answer to this question. We assume that the Rich Investor acquires blocks at date 1 if he is indifferent between acquiring blocks at dates 0 and 1 .

\section{Proposition 3: (Optimality of State-Contingent Allocation of the Rich Investor's}

Wealth) Suppose a large enough measure of firms do not have a date 0 blockholder so that the Rich Investor could feasibly invest all his wealth at date 1 in distressed firms that had no blockholder at date 0. Then the Rich Investor chooses to invest all his wealth at date 1 if and only if the following condition, (*), holds:

$$
\begin{aligned}
& \left(\frac{1}{\pi(1-\tilde{\rho}) P \lambda+c}\right)\left(\pi \int_{\tilde{\rho}}^{1}(\rho H(\lambda)-P) \lambda d \rho-c\right) \geq \kappa\left(\pi-\pi_{L}\right) \delta \int_{\rho^{+}}^{1}\left(\rho H(1)-L_{2}\right) d \rho, \\
& \text { where } \kappa=\frac{1}{(1-\delta) R+\delta\left[L_{2}+\pi_{L} \int_{\rho^{+}}^{1}\left(\rho H-L_{2}\right) d \rho\right]} \text {. If he cannot spend all his }
\end{aligned}
$$

wealth at date 1, he invests as much of his wealth as possible at date 1 and the remainder in date 0 blocks if and only if (*) holds.

\section{Proof: See Appendix A.}

\footnotetext{
${ }^{18}$ If there are sufficiently few firms having no date 0 blockholder, this source of inefficiency is absent. The
} 
Condition (*) simply compares the Rich Investor's profit from each strategy, investing at date 0 versus investing at date 1 . The Proposition has one key insight that is discussed in the form of a Corollary.

Corollary 1: The Rich Investor prefers to invest his wealth in the date 1 stock market if and only if $\delta \leq \bar{\delta}$, where the critical value, $\bar{\delta}$, depends only on exogenous parameters.

Proof: See Appendix A.

Corollary 1 formalizes a basic point. If the Rich Investor buys a position at date 0 , he is wasting his agency-cost free capital because he is investing even in the good state in which there is no agency conflict. Then his monitoring and restructuring activity is not needed. An agency conflict arises only in the bad state at date 1. If there is a sufficiently large chance that the firm will receive good news (be in the good state) at date 1, and hence not need a restructuring, the Rich Investor is better off deploying his wealth at date 1, contingent on news that the agency conflict matters: here, contingent on bad news arriving. However, because date 1 blockholding is associated with the inefficiencies described in Proposition 2, the Rich Investor prefers to invest his wealth at date 0 if the chance of bad news arriving is large enough.

Clearly, if the Rich Investor's wealth is very limited, he invests only in date 1 blocks. ${ }^{19}$ If the Rich Investor cannot investigate all firms receiving bad news and then acquire blocks in all the attractive firms that he investigated, investing a marginal dollar at date 0 implies that he has to forgo the more attractive return in the date 1 stock market.

\section{The Firms' Date 0 Equity Ownership Structure}

In the last section, we isolated the determinants of the Rich Investor's decision about the allocation of his wealth between dates 0 and 1. The Rich Investor's investment 
choice affects and is affected by the firms' initial equity ownership structures, which are analyzed in this section. We show that there is a variety of equity ownership structures that can occur, even though all firms are identical as of date 0 .

\section{A. The Coexistence of Block Ownership and Dispersed Ownership}

If the Rich Investor is not active in the date 1 stock market, i.e., there is no takeover market, then a policy of issuing shares to many small investors is strictly dominated. All firms will be owned at date 0 by blockholders (the Rich Investor or institutional investors). The reason is that if the Rich Investor is not active in the date 1 stock market, firms that have no date 0 blockholder are never restructured. However, if the Rich Investor is active in the date 1 stock market, the restructuring policy implemented in a firm that has no date 0 blockholder may become sufficiently efficient to induce firms to have an initially dispersed ownership. The following Proposition characterizes the unique equilibrium in the perhaps most interesting parameter region. It shows that firms with dispersed and concentrated ownership can coexist although all firms are identical. It is assumed that firms have no date 0 blockholder if their value is identical with and without a date 0 blockholder.

Proposition 4: Suppose condition (*) holds. If the Rich Investor's wealth is scarce such that $W<\delta[c+\pi(1-\tilde{\rho}) \lambda P]$ and if

$$
\begin{aligned}
& (* *)\left(1-\frac{\tilde{\mu}}{\delta}\right) L_{2}+\frac{\tilde{\mu}}{\delta}\left\{(1-\pi) L_{2}+\pi\left[\int_{0}^{\tilde{\rho}} L_{2} d \rho+\int_{\tilde{\rho}}^{1}[\lambda P+(1-\lambda) \rho H(\lambda)] d \rho\right]\right\} \\
& <L_{2}+\pi_{L} \int_{\rho^{+}}^{1}\left(\rho H-L_{2}\right) d \rho-c \text { and } \\
& (* * *) L_{2}+\pi_{L} \int_{\rho^{+}}^{1}\left(\rho H-L_{2}\right) d \rho-c \\
& \leq(1-\pi) L_{2}+\pi\left\{\int_{0}^{\tilde{\rho}} L_{2} d \rho+\int_{\tilde{\rho}}^{1}[\lambda P+(1-\lambda) \rho H(\lambda)] d \rho\right\}
\end{aligned}
$$

then at date 0 a measure $1>x^{*}>\frac{W}{\pi(1-\tilde{\rho}) P \lambda+c}$ of firms issue shares only to individual small investors and a measure $1-x^{*}$ of firms issue shares to an institutional investor at

\footnotetext{
${ }^{19}$ Section IV endogenizes the number of firms having no date 0 blockholder. In that section, Proposition 4 gives an upper bound on the wealth of the Rich Investor that formalizes its scarcity.
} 
date 0.

Proof: See Appendix A.

The Proposition shows that firms with and without a date 0 blockholder can coexist even though all firms are identical. The situation is portrayed in Figure $2 .{ }^{20}$ Note that the efficiency of the restructuring decisions made by an institutional investor does not depend on the fraction of firms having no date 0 blockholder. Hence, in Figure 2, the equity value for firms obtaining funds from institutional investors is a horizontal line. However, the efficiency of the restructuring policies in firms that have no date 0 blockholder decreases in the fraction of firms that have no date 0 blockholder. In particular, the larger the fraction of firms having no date 0 blockholder, the more likely it is that an individual firm will not be investigated by the Rich Investor after the firm has received bad news. This is because the Rich Investor's wealth is limited. ${ }^{21}$ The fraction of firms that have no date 0 blockholder adjusts such that all firms are indifferent between obtaining funds from an institutional investor and from individual small investors. Notice that takeovers occur only because the superior monitoring ability of the Rich Investor, who is active in the takeover market, compensates for the inefficiencies associated with state-contingent blockholding described in Proposition 2.

For coexistence to occur, conditions $(* *)$ and $(* * *)$ must be satisfied. Condition $(* *)$ says that the value of a firm with initially dispersed ownership (without a date 0 blockholder) is smaller than that of a firm with an institutional date 0 blockholder if all firms have an initially dispersed ownership. Then, the probability that an individual firm is investigated by the Rich Investor after receiving bad news at date 1 is as low as possible. If despite this low probability of investigation firms would prefer to rely on the takeover mechanism for monitoring, no firm would rely on the monitoring of an institutional date 0 blockholder.

\footnotetext{
${ }^{20}$ The explicit solution for $x^{*}$ is given in Proposition 8 .

${ }^{21}$ If $W \geq \delta[c+\pi(1-\tilde{\rho}) \lambda P]$ and (*) holds, then firms with and without date 0 blockholder cannot coexist. The reason is that then any firm that has no date 0 blockholder will be investigated for sure by the Rich Investor at date 1 . Thus, if (***) holds, no firm has a date 0 blockholder. If (***) does not hold, all firms have a date 0 blockholder.
} 
Condition (***) says that the value of a firm with an institutional date 0 blockholder is not larger than the value of a firm with initially dispersed ownership (without a date 0 blockholder) even if there are so few firms with initially dispersed ownership that each of them is guaranteed to be investigated by the Rich Investor after receiving bad news at date 1. If despite this maximal probability of an investigation by the Rich Investor firms would prefer to rely on institutional monitoring, no firm would have an initially dispersed ownership.

Coexistence of intermediated and nonintermediated finance - in the debt market - has been shown in models with heterogeneous firms. For instance, Chemmanur and Fulghieri (1994) develop a model in which firms that are more likely to become distressed obtain loans from financial intermediaries while the other firms issue bonds to many small investors. In contrast to that literature, we obtain coexistence of financial intermediaries and securities markets although all firms are identical. In the equilibrium described in Proposition 4, the Rich Investor deploys his agency-cost free capital in the date 1 stock market. Hence, information production is more efficient for firms issuing shares to many small investors at date 0 if the Rich Investor investigates these firms at date 1 . However, institutional investors hold a larger block and do not have to share the surplus from their restructuring activity with other investors. Hence, they make the better decisions once they become informed about the firm's quality.

If a firm was certain that the Rich Investor would investigate it once it received bad news, it would strictly prefer obtaining funds from individual small investors over

obtaining funds from institutional investors. The indifference of firms between dispersed and concentrated ownership arises because ex ante a firm that obtains funds from individual small investors takes into account the likelihood of receiving bad news, but also of not being investigated by the Rich Investor in that event.

\section{B. Only Block Ownership or Only Dispersed Ownership}

If the restructuring policy implemented by the Rich Investor is sufficiently more efficient than that implemented by an institutional investor, then all firms have an initially dispersed ownership, and there are no institutional blockholders. On the other hand, it may be the case that all firms prefer to have a blockholder at date 0 . This can occur if the 
inefficiencies in the restructuring policy implemented by the Rich Investor at date 1 (see Section III.C) are particularly severe. In that case, no firm wants to rely on the restructuring policy of the Rich Investor at date 1 even if it is guaranteed that the Rich Investor will investigate all firms with initially dispersed ownership after bad news arrival at date 1 because there are so few of them. Understanding this, the Rich Investor will buy blocks only at date 0 . These results are summarized in Proposition $5 .^{22}$

Proposition 5: If (*) holds and (**) does not hold, then no firm has a date 0 blockholder. If (***) does not hold, then all firms have a date 0 blockholder, and the Rich Investor invests all his wealth in date 0 blocks.

Proof: See Appendix A.

Recall that if the Rich Investor is not active in the date 1 stock market, firms that have no date 0 blockholder are never restructured. Then, having an initially dispersed ownership is always less efficient in terms of restructuring decisions and strictly dominated by having a date 0 blockholder, even if he is an institutional investor. This is formalized in:

Proposition 6: Suppose condition (*) does not hold. Then all firms have a date 0 blockholder.

Proof: See Appendix A.

\section{The Rich Investor's Monitoring Advantage and Equity Ownership Structures}

The firms' initial ownership structures depend on the degree of monitoring that institutional investors can offer despite the agency conflict they suffer from.

\footnotetext{
${ }^{22}$ Conditions $(* *)$ and $(* * *)$ are from Proposition 4. Condition $(*)$ is from Proposition 3.
} 
Proposition 7: All firms have a date 0 blockholder if

$\pi_{L}>\frac{c+\pi\left(\int_{\tilde{\rho}}^{1}\left(\lambda P+(1-\lambda) \rho H(\lambda)-L_{2}\right) d \rho\right)}{\int_{\rho^{+}}^{1}\left(\rho H-L_{2}\right) d \rho} \equiv \tilde{\pi}_{L} . \quad$ If $(*)$ holds and

$\tilde{\pi}_{L} \geq \pi_{L}>\frac{\left.c+\frac{\tilde{\mu}}{\delta} \pi\left\{\int_{\tilde{\rho}}^{1}\left[\lambda P+(1-\lambda) \rho H(\lambda)-L_{2}\right] d \rho\right]\right\}}{\int_{\rho^{+}}^{1}\left(\rho H-L_{2}\right) d \rho} \equiv \pi_{L}$ firms with and without a date 0

blockholder coexist. If (*) holds and $\pi_{L} \leq \bar{\pi}_{L}$, no firm has a date 0 blockholder.

Proof: See Appendix A.

The intuition behind this result is as follows: If the institutional investors are very bad at monitoring $\left(\pi_{L} \leq \bar{\pi}_{L}\right)$, then all firms prefer to rely on the state-contingent blockholding of the Rich Investor and have an initially dispersed ownership structure. Although an individual firm's chance of being restructured by the Rich Investor is low since all firms rely on his scarce monitoring resources, firms are still better off when they rely on his monitoring than when they rely on the inefficient monitoring by an institutional date 0 blockholder. Of course, for firms to be willing to have no date 0 blockholder and instead rely on the Rich Investor's state-contingent blockholding, the Rich Investor must prefer to allocate his wealth in a state-contingent way. This is the case if $\left(^{*}\right)$ is satisfied.

If the institutional investors are neither particularly good nor particularly bad at monitoring $\left(\bar{\pi}_{L}<\pi_{L} \leq \tilde{\pi}_{L}\right)$, then firms with and without a date 0 blockholder coexist. The number of firms having an initially dispersed ownership structure adjusts so that firms are indifferent between initially dispersed and concentrated ownership.

Finally, no firm has an initially dispersed ownership structure if institutional investors are sufficiently effective at monitoring $\left(\pi_{L}>\tilde{\pi}_{L}\right)$. Then entrepreneurs prefer to rely on the permanent monitoring by the institutional investors rather than the takeover mechanism for firms with dispersed ownership - even if the Rich Investor would prefer to buy blocks at date 1 . While the Rich Investor is a little better at information production, the inefficiencies associated with state-contingent blockholding by the Rich Investor 
demonstrated in Proposition 2 make it more attractive to have an institutional date 0 blockholder.

\section{Equity Ownership Structure and the Likelihood of Distress}

A critical parameter of the model is the probability of firms becoming distressed. A distressed firm may need a blockholder to implement a restructuring against management's will. As we saw in Corollary 1, the Rich Investor's optimal investment strategy is intimately related to this probability. It is also an important determinant of the initial equity ownership structure.

Proposition 8: Suppose that $\delta \leq \hat{\delta}$ where $\hat{\delta}$ solves the following equation:

$$
\begin{aligned}
& \left(1-\frac{\tilde{\mu}}{\delta}\right) L_{2}+\frac{\tilde{\mu}}{\delta}\left\{(1-\pi) L_{2}+\pi\left[\int_{0}^{\tilde{\rho}} L_{2} d p+\int_{\tilde{\rho}}^{1}[\lambda P+(1-\lambda) \rho H(\lambda)] d \rho\right]\right\}= \\
& L_{2}+\pi_{L} \int_{\rho^{+}}^{1}\left(\rho H-L_{2}\right) d \rho-c .
\end{aligned}
$$

Then no firm has a date 0 blockholder. Suppose $\hat{\delta}<\delta \leq \bar{\delta}$ where $\bar{\delta}$ was defined in Corollary 1. Then the measure of firms having no date 0 blockholder is $x^{*}=\frac{\tilde{\mu}}{\delta}\left\{\frac{\pi \int_{\tilde{\rho}}^{1}\left(\lambda P+(1-\lambda) \rho H(\lambda)-L_{2}\right) d \rho}{\pi_{L} \int_{\rho^{+}}^{1}\left(\rho H-L_{2}\right) d \rho-c}\right\}$. In this region, $\frac{\partial x^{*}}{\partial \delta}<0$. If $\delta>\bar{\delta}$, all firms have a date 0 blockholder.

Proof: See Appendix A.

If the probability of bad news arriving is very low (of course, this critical probability depends on the other parameters of the model), having an initially dispersed ownership and hoping to be investigated by the Rich Investor at date 1 is very attractive. Even if all firms have an initially dispersed ownership, this is more profitable than obtaining funds from an institutional investor. This is because for a low $\delta$ there is a high probability of being investigated by the Rich Investor despite his limited wealth. The reason is that there are so few distressed firms with dispersed ownership that the Rich Investor can investigate. For an intermediate probability of bad news arrival, the Rich Investor still invests all his wealth 
in acquiring date 1 blocks. However, the more firms obtain nonintermediated finance, the lower is the probability for each individual firm that the Rich Investor will investigate it after bad news arrives at date 1. To ensure that firms are indifferent between intermediated and nonintermediated finance, the probability that the Rich Investor investigates an individual firm after bad news arrives at date 1 must be a particular number. Hence, if the measure of firms that become distressed $(\delta$ ) increases, the measure of firms with initially dispersed ownership $\left(x^{*}\right)$ must decrease. Finally, if the probability of bad news arrival is sufficiently high, the Rich Investor invests all his wealth in date 0 blocks. Then having no date 0 blockholder is dominated because a firm without a date 0 blockholder is never restructured.

\section{The Role and Importance of An Active Block Market at Date 1}

In this section, we assume that the block market at date 1 is active, i.e., we reverse assumption A10 and assume instead:

A10B. Observable Information Production. It is observable whether an investor has investigated a firm or not.

Now the Rich Investor may buy a block from an institutional investor at date 1 . The price is formed such that the institutional investor makes as much money by selling the block as by holding on to it. This is because institutional investors are competitive and make zero profits.

Lemma 6: Suppose A10B holds. If the Rich Investor buys a block at date 1 from an institutional investor, he buys before he or the institutional investor has investigated the firm.

\section{Proof: See Appendix A.}

If the Rich Investor investigated before he bought a firm, the market for block transfers between institutional investors and the Rich Investor would become inactive for the 
reasons that were discussed after Lemma 4. For trade between an institutional investor and the Rich Investor to occur, the institutional investor must be confident that the Rich Investor has not secretly investigated the firm before he makes an offer to buy it. This is possible because it is observable whether the rich Investor investigates a firm or not.

Lemma 7: Suppose A10B holds. If the Rich Investor buys a block from an institutional investor at date 1, then he pays (per measure 1 of firms) the price $P^{I I}$ where

$$
\begin{aligned}
& P^{I I} \equiv L_{2}+\pi_{L} \int_{\rho^{+}}^{1}\left(\rho H-L_{2}\right) d \rho-c \text { and makes a profit of } \Pi \text { where } \\
& \Pi \equiv\left(\pi-\pi_{L}\right)\left(\int_{\rho^{+}}^{1} \rho H-L_{2}\right) d \rho .
\end{aligned}
$$

Proof: See Appendix A.

With these preliminary results we can now investigate how the Rich Investor and the institutional investors interact at date 1 .

\section{A. The Rich Investor and the Date 1 Block Market}

Opening the market for block trades between institutional investors and the Rich Investor makes the date 0 investment strategy suboptimal for the Rich Investor:

Proposition 9: Suppose A10B holds. The Rich Investor always invests in date 1 blocks rather than in date 0 blocks.

Proof: See Appendix A.

This is the main new result once we allow for block trades between institutional investors and the Rich Investor. Now the state-contingent allocation of the Rich Investor's wealth is a dominant strategy. The intuition behind this result is as follows: Buying a block at date 0 , i.e., before the realization of the state of the world, is not profit-maximizing for the Rich Investor because he then wastes his agency-cost free capital in the case that the firm does not become distressed. In this case, the firm does not need his monitoring and 
restructuring services. Buying a firm from an institutional investor at date 1 after this firm has experienced bad news (but before investigation) allows the Rich Investor to concentrate his agency-cost free wealth where it is most productive: when agency conflicts are severe and hence a blockholder may be needed to implement a restructuring. Buying from an institutional investor at date 1 has no disadvantages as compared to assembling a block at date 0 . Hence, buying at date 0 is strictly dominated.

Should the Rich Investor buy from institutions or buy from small investors? The next Proposition shows the conditions under which the Rich Investor prefers to buy a date 1 block from dispersed investors and the conditions under which he prefers to buy from an institutional investor. It is assumed that the Rich Investor buys a block from many small investors if he is indifferent between buying from many small investors and an institutional investor. The following Proposition uses the symbols $P^{I I}$ and $\Pi$, which were defined in Lemma 7.

Proposition 10: Suppose A1OB holds. The Rich buys blocks at date 1 from many dispersed investors if (****) is fulfilled where

$$
(* * * *) \frac{1}{\pi(1-\tilde{\rho}) P \lambda+c}\left(\pi \int_{\tilde{\rho}}^{1}(\rho H(\lambda)-P) \lambda d \rho-c\right) \geq \frac{1}{P^{I I}+c} \Pi . \text { If }(* * * *) \text { is not }
$$

fulfilled, the Rich Investor buys blocks at date 1 from an institutional investor.

\section{Proof: See Appendix A.}

There are two disadvantages in buying a block from many small investors as opposed to buying from an institutional investor: First, the free-rider problem implies that the Rich Investor has to share some of the surplus his restructuring activity will generate with the existing small investors. Second, he can buy only a limited block, $\lambda<1$. In the model of Appendix B, the extent of the free-rider problem is determined by the extent of liquidity trading at date 1 . On the other hand, there is also an important advantage to buying from dispersed investors: The Rich Investor may create a larger increase in firm value than if he buys from an institutional investor. While institutional investors are able to restructure the firm and hence increase firm value, dispersed investors cannot do so and hence the 
Rich Investor may add more value when he trades with the dispersed investors. Condition $(* * * *)$ formalizes how these advantages and disadvantages in buying from many dispersed investors affect the Rich Investor's choice at date 1.

\section{B. The Variety of Equity Ownership Structures With an Active Block Market}

The results on equity ownership structures in Section IV survive under slightly different conditions. Coexistence of firms with dispersed and concentrated ownership at date 0 survives but there is one change: condition $(*)$ is replaced with condition (****). Moreover, there are again parameter regions in which all firms have dispersed ownership or in which all firms have concentrated ownership at date 0. Propositions 11 and 12 summarize these results, using condition (****) defined in Proposition 10 and conditions $(* *)$ and $(* * *)$ defined in Proposition $4^{23}$ :

Proposition 11: Suppose A10B holds. If (****) does not hold, all firms have a date 0 blockholder. If $W<\delta[c+\pi(1-\tilde{\rho}) \lambda P]$ and (****) holds and also (**) and (***) hold, firms with dispersed and concentrated ownership at date 0 coexist. If (****) holds and (**) does not hold, then all firms have a dispersed ownership at date 0. If (***) does not hold, then all firms have a date 0 blockholder.

Proof: See Appendix A.

Proposition 12: All firms have a date 0 blockholder if

$$
\begin{aligned}
& \pi_{L}>\frac{c+\pi\left(\int_{\tilde{\rho}}^{1}\left(\lambda P+(1-\lambda) \rho H(\lambda)-L_{2}\right) d \rho\right)}{\int_{\rho^{+}}^{1}\left(\rho H-L_{2}\right) d \rho} \equiv \tilde{\pi}_{L} . \text { If }(* * * *) \text { holds and } \\
& \tilde{\pi}_{L} \geq \pi_{L}>\frac{\left.c+\frac{\tilde{\mu}}{\delta} \pi\left\{\int_{\tilde{\rho}}^{1}\left[\lambda P+(1-\lambda) \rho H(\lambda)-L_{2}\right] d \rho\right]\right\}}{\int_{\rho^{+}}^{1}\left(\rho H-L_{2}\right) d \rho} \equiv \bar{\pi}_{L}, \text { firms with and without a date } 0
\end{aligned}
$$

blockholder coexist. If (****) holds and $\pi_{L} \leq \bar{\pi}_{L}$, no firm has a date 0 blockholder.

\footnotetext{
${ }^{23}$ If $W \geq \delta[c+\pi(1-\tilde{\rho}) \lambda P]$ and $(* *)$ and $(* * *)$ hold, no firm has a date 0 blockholder.
} 
Proof: See Appendix A.

This result characterizes firms' initial ownership structure as a function of the extent of the agency conflict within institutional investors. The intuition is the same as the intuition behind Proposition 7.

\section{Conclusion}

Agency problems in corporations occur when there is a separation of ownership and control. This means that there is a scarcity of rich investors with "agency-cost free" capital. Rich investors are then special because they are scarce. That is, in contrast to institutional investors, they do not face agency problems. Hence, they are the most effective monitors of management. We analyze the allocation of this scarce resource and show the implications for the identity of blockholders, the market for blocks of shares, the role of hostile takeovers, and the equity ownership structure of the economy.

Hostile takeovers allow rich investors to deploy their scarce monitoring resources where they are needed most, in situations in which agency conflicts are potentially severe -- financial distress, mature industries with excess cash, CEO succession problems, etc. Rich investors may concentrate on allocating their agency-cost free capital to the takeover market. When the informational environment allows the market for block transfers from institutional investors to rich investors to be active, the rich investors always restrict their investments to the takeover market. Since only the best monitors, rich investors with agency-cost free capital, are active in the takeover market, hostile takeovers can be an efficient monitoring device despite the inefficiencies associated with the free-rider problem and despite the alternative of permanent institutional blockholding. However, hostile takeovers do not need to be a feature of the corporate control environment. Whether rich investors are active in the takeover market or are permanent blockholders depends on the likelihood of agency conflicts, and hence the need for monitoring, and on the relative efficiency of the rich investors' monitoring compared to institutional monitoring. 
In contrast to rich investors, institutional investors never engage in hostile takeovers, because they are not scarce. But, while institutional investors cannot replicate agency cost-free capital, they have two important roles. First, they provide some monitoring of management as permanent blockholders. And second, they can act as block providers for rich investors, facilitating takeovers. Because firms with initially dispersed ownership can rely on the monitoring through the takeover market, it can be optimal to have no blockholder (initially). Neither concentrated nor dispersed ownership need be dominant ownership structures. Firms with institutional block ownership and dispersed ownership can coexist for otherwise identical firms. The rich investors' investment strategy is a important determinant of firms' equity ownership structures.

There are several additional issues that could be analyzed in the framework of this paper. For example, it is often claimed that some firms are too big to be monitored effectively. If the wealth of rich individuals is scarce, even they may not be able to hold a block of sufficient size to implement a restructuring or they might be too risk averse to hold substantial blocks in large firms. In these cases, institutional investors who are less effective at monitoring must monitor large firms. To address this issue, our model would have to be extended to allow for some firm heterogeneity ex ante.

It would also be interesting to say more about the role of liquid markets. While it is clear in our model that liquid markets allow scarce monitoring resources to be deployed to the firms that need them most, there is no reason to expect a monotone relationship between the liquidity of the stock market and the efficiency of monitoring. To address this issue, it would be helpful to endogenize the size of the block that the Rich Investor can acquire when he buys it from many dispersed investors at date 1 . 


\section{Appendix A: Proofs}

Proof of Lemma 1: If the date 0 blockholder does not restructure, his payoff is $\theta L_{2}$. If he restructures, his expected payoff is $\theta \rho H(\theta)$. Hence, the date 0 blockholder restructures if and only if $\rho H(\theta) \geq L_{2}$ or $\rho \geq \frac{L_{2}}{H(\theta)} \equiv \rho^{+}(\theta)$. QED

Proof of Lemma 2: Investors and their funds are competitive so they acquire blocks from the entrepreneurs at date 0 at a price equal to the value of a firm that has anstitutional investor as a date 0 blockholder. Hence, an institutional investor bidding for a fraction $\theta$ of a firm can offer $(1-\delta) R+\delta\left\{L_{2}+\pi_{L} \int_{\rho^{+}(\theta)}^{1}\left(\rho H(\theta)-L_{2}\right) d \rho\right\}-I$ per measure 1 of the firm where $\rho^{+}(\theta)$ is defined by $\rho^{+}(\theta)=\frac{L_{2}}{H(\theta)}$. This expression is maximized at $\theta=1$ because $H(1)$ is larger than $H(\theta)$ for $\theta<1$ due to $\mathrm{A} 5$ and also, as a consequence, $\rho^{+}(1)<\rho^{+}(\theta)$ for $\theta<1$. Suppose that the Rich Investor is not bidding in the auction. The institutional investor who offers to buy the whole firm wins the auction while he still breaks even. Alternatively, suppose that the Rich Investor decides to acquire a block at date 0 . Because shares are initially sold in a second price auction, the Rich Investor pays the offer of the second highest bidder, an institutional investor. This is, per measure 1 of firms, $(1-\delta) R+\delta\left\{L_{2}+\pi_{L} \int_{\rho^{+}}^{1}\left(\rho H(1)-L_{2}\right) d \rho\right\}-I$. Hence, the Rich Investor wants to maximize the firm value under his ownership, because it is the difference between this and the price he pays that determines his profit. By A5, firm value under the Rich Investor's ownership is maximized at $\theta=1$. Hence, he offers to buy the whole firm. Since all date 0 blockholders own the entire firm, they restructure if and only if $\rho \geq \frac{L_{2}}{H(1)} \equiv \rho(1) \equiv \rho^{+}$. QED

Proof of Lemma 3: To calculate the Rich Investor's profits per measure 1 of firms he acquires at date 0 , we only need to calculate the difference between the value of the firm with the Rich Investor as date 0 blockholder and the value of the firm with an institutional 
investor as date 0 blockholder. This difference in firm value is $\left(\pi-\pi_{L}\right) \delta \int_{\rho^{+}}^{1}\left(\rho H(1)-L_{2}\right) d \rho$. This is the amount the Rich Investor earns per measure 1 of firms he acquires at date 0 . Since the price for a measure 1 of firms is $(1-\delta) R+\delta\left[L_{2}+\pi_{L} \int_{\rho^{+}}^{1}\left(\rho H-L_{2}\right) d \rho-c\right]-I$ and the Rich Investor has to spend $I$ per measure 1 of all firms for investment and the investigation cost $c$ (per measure 1 of firms) for the firms that he investigates, he can acquire a measure $\frac{W}{(1-\delta) R+\delta\left[L_{2}+\pi_{L} \int_{\rho^{+}}^{1}\left(\rho H-L_{2}\right) d \rho\right]}$ of firms. QED

Proof of Proposition 1: If the institutional investor buys a firm at date 1, he cannot make a profit even after having learned that $\rho \geq \rho^{+}$. Since the institutional investors are not scarce, there is at least one other institutional investor investigating the firm. If one institutional investor learns $\rho$, so does the other, by assumption. Due to the competitive behavior of the institutional investors, the price they offer to buy the firm will be equal to its value after a restructuring, given $\rho$. But then, the institutional investor cannot cover his investigation cost and loses money. Hence, no institutional investor attempts to investigate a firm at date 1 . QED

Proof of Lemma 4: We can restrict ourselves to potential sales of the whole firm, by A5. Note that an institutional investor will not sell the firm for less than $L_{2}$ (per measure 1 of firms). The reason is that the institutional investor can always achieve a payoff of $L_{2}$ by holding on to the firm and not restructuring it. There are four possible equilibria with trade: (1) trade if the Rich Investor investigates the firms before trading, but the institutional investors do not investigate; (2) trade if the Rich Investor does not investigate the firms before trading, but the institutional investors do investigate; (3) trade if neither the Rich Investor nor the institutional investors investigate the firm before trading; and (4) trade if both the Rich Investor and the institutional investors investigate the firms before trading. 
Case (1): Suppose that there is an equilibrium with trade in which the Rich Investor investigates the firms before trading while the institutional investors do not investigate. If the Rich Investor learns that $\rho<\rho^{+}$, he will not make an offer since the firm is worth $L_{2}$ to him and the institutional investor will not sell for a price below $L_{2}$ (per measure 1 of firms). If the Rich Investor does not learn $\rho$, he will not offer more than $L_{2}$ because he will not restructure by $A 4$. If the Rich Investor learns that $\rho \geq \rho^{+}$, he may want to make an offer. But the institutional investor understands that this is the only instance in which there might be an offer above $L_{2}$. He also understands that the Rich Investor will not make an offer above the true value of the firm, given $\rho$, because otherwise the Rich Investor would be better off not buying the firm. But then the institutional investor is at least as well off holding the firm and restructuring it himself, obtaining the firm's true value.

Case (2): Similarly, there is no equilibrium in which the institutional investor investigates, but the Rich Investor does not, and there is trade. Suppose the price is $P^{0}$ (per measure 1 of firms). If the Rich Investor sticks to his equilibrium strategy of not investigating, his profit per dollar invested is $\frac{1}{c+P^{0}}\left((1-\pi)\left(L_{2}-P^{0}\right)+\pi \int_{0}^{\rho^{+}}\left(L_{2}-P^{0}\right) d \rho+\pi \int_{\rho^{+}}^{1}\left(\rho H-P^{0}\right) d \rho-c\right)$. If the Rich Investor instead investigated before making offers to buy firms, his profit per dollar invested would be $\frac{1}{c+\pi\left(1-\rho^{+}\right) P^{0}}\left(\pi \int_{\rho^{+}}^{1}\left(\rho H-P^{0}\right) d \rho-c\right)$. This is larger than the previous expression because $P^{0} \geq L_{2}$ and $\frac{1}{c+P^{0}}<\frac{1}{c+\pi\left(1-\rho^{+}\right) P^{0}}$. Hence, the Rich Investor would have an incentive to deviate to investigating before buying, and thus the candidate equilibrium is not an equilibrium.

Case (3): There is also no equilibrium with trade in which neither the Rich Investor nor the institutional investor investigate before trading. Suppose to the contrary that there was an equilibrium in which neither the institutional investor nor the Rich Investor has investigated the firm, but the Rich Investor buys it. Since the institutional investors behave competitively, they would sell the firm at the price that would make them indiffer- 
ent between holding on to the block and selling it. This price is: $L_{2}+\pi_{L} \int_{\rho^{+}}^{1}\left(\rho H-L_{2}\right) d \rho-c \equiv P^{I I}$. Then the Rich investor's profit per dollar invested is $\frac{1}{c+P^{I I}}\left((1-\pi)\left(L_{2}-P^{I I}\right)+\pi \int_{0}^{\rho^{+}}\left(L_{2}-P^{I I}\right) d \rho+\pi \int_{\rho^{+}}^{1}\left(\rho H-P^{I I}\right) d \rho-c\right)$. The Rich Investor can do better by investigating and only offering to buy the firms that he would restructure, i.e., with $\rho \geq \rho^{+}$. Then he would make $\frac{1}{c+\pi\left(1-\rho^{+}\right) P^{I I}}\left(\pi \int_{\rho^{+}}^{1}\left(\rho H-P^{I I}\right) d \rho-c\right)$ per dollar invested. The latter expression is larger than the previous expression because $P^{I I}>L_{2}$ and $\frac{1}{c+P^{I I}}<\frac{1}{c+\pi\left(1-\rho^{+}\right) P^{I I}}$. Hence, investigating before making an offer and buying a firm is a profitable deviation for the Rich Investor. Thus, there is no equilibrium with trade in which neither the Rich Investor nor the institutional investor investigate the firm before trading.

Case (4): Finally, we have to show that there is no equilibrium with trade if both the institutional investors and the Rich Investor investigate before buying. If the Rich Investor learns $\rho<\rho^{+}$, the firm is worth $L_{2}$ and he will not make an offer above $L_{2}$. If he does not learn $\rho$, then the Rich Investor will not make an offer above $L_{2}$ either. If the Rich Investor makes an offer at a particular price above $L_{2}$ (call it $P^{1}$ ), the institutional investor will accept only if he has learned that the true value of the firm is equal to or lower than the offer (including the case when he has learned that $\rho<\rho^{+}$) or if he has not learned $\rho$. If his offer was accepted, the Rich Investor loses on the overvalued accepted offers (for which the institutional investor learned $\rho$ ) and cannot gain on the firms for which the institutional investor did not learn $\rho$ (by A4) as a compensation for these losses. Note that trading at a price $L_{2}$ would protect the Rich Investor from losing money. Hence it could potentially be an equilibrium for the institutional investor to sell all firms for which he did not learn $\rho$ or for which he learned $\rho<\rho^{+}$to the Rich Investor at the price $L_{2}$. However, there are no gains from trade in this case. Hence there is no trade. The reason why there are no gains from trade is as follows: The institutional investor would not get a higher payoff than when holding on to the firms and not restructuring them. Moreo- 
ver, the Rich Investor would not gain from trade either since the firms traded to him would be worth $L_{2}$ to him as well. This is obvious for the firms for which the institutional investor learned $\rho<\rho^{+}$. It is also true for the firms for which the institutional investor did not learn $\rho$. By assumption, then the Rich Investor cannot learn $\rho$ either if he attempts to do so. We have shown above that the Rich Investor does not make an offer above $L_{2}$ if he does not learn $\rho$ or if he learns $\rho<\rho^{+}$. As a consequence, the only instance in which the Rich Investor would make an offer higher than $L_{2}$ would be if he learns $\rho \geq \rho^{+}$. But the institutional investor understands this and also knows that then the Rich Investor will make an offer not higher than the true value of the firm. Hence, the institutional investor is at least as well off if he holds on to the firm and restructures it himself. QED

Proof of Lemma 5: We have shown in Proposition 1 that institutional investors never acquire blocks at date 1 . It was already shown in Lemma 4 that the Rich Investor never buys a block at date 1 from an institutional investor. Hence, the only other possibility is for a date 0 blockholder to sell to small investors at date 1 . But then, a measure 1 of firms is known to be worth $L_{2}$ since the small investors cannot restructure a firm. Hence, the price at which a measure 1 of firms can be sold is $L_{2}$. This payoff can also be obtained by holding on to the firm and not restructuring it. Hence, there is no gain from selling the shares. QED

Proof of Proposition 2: Without specifying a particular price formation mechanism, we cannot give an explicit solution for $\tilde{\rho}$. However, a necessary condition for the optimal solution is that $\tilde{\rho} \geq \frac{P}{H(\lambda)}$ : if this was not the case, the Rich Investor could increase his profits by not buying the firms with $\tilde{\rho}<\frac{P}{H(\lambda)}$ on which he loses money. By assumption, $P \geq L_{2}$ and by A5, $H(\lambda)<H$ if $\lambda<1$. Hence, $\tilde{\rho}>\rho^{+}$if $\lambda<1$ or $P>L_{2}$. Given that the 
Rich Investor buys if and only if he learns that $\rho \geq \tilde{\rho}$, he can investigate a measure $\frac{W}{\pi(1-\tilde{\rho}) P \lambda+c} \equiv \tilde{\mu}$ of all distressed firms. QED

Proof of Proposition 3: Per dollar invested at date 0 the Rich Investor's profits are $\kappa\left(\pi-\pi_{L}\right) \delta \int_{\rho^{+}}^{1}\left(\rho H(1)-L_{2}\right) d \rho$, as was calculated in Lemma 3. Alternatively, the Rich Investor can invest his wealth to acquire blocks in distressed firms at date 1 . Then, his profits are, per dollar invested, $\left(\frac{1}{\pi(1-\tilde{\rho}) P \lambda+c}\right)\left(\pi \int_{\tilde{\rho}}^{1}(\rho H(\lambda)-P) \lambda d \rho-c\right)$, with $\tilde{\rho}$ defined in Proposition 2. Clearly, both the profits from investing at date 0 and from investing at date 1 are linear functions of the wealth invested in each alternative. Hence, the Rich Investor will invest as much as possible of his wealth in the date 1 stock market if and only if condition (*) holds (assuming that he breaks an indifference in favor of the date 1 stock market). Notice that if the Rich Investor invests all his wealth at date 0, no firm will choose to have an initially dispersed ownership and all firms will want to obtain funds from the Rich Investor rather than an institutional investor at date 0. Hence, if the Rich Investor wants to invest all his wealth at date 0 , he is always able to do so. QED

Proof of Corollary 1: First, recall that $\frac{\partial \tilde{\rho}}{\partial \delta}=0$ since $\delta$ does not appear in the Rich Investor's objective function directly and, by A8, also not indirectly through $P$. Hence, the left hand side of $(*)$ does not depend on $\delta$. The right hand side of $(*)$ is a strictly increasing function of $\delta$ because:

$$
\frac{\partial \kappa}{\partial \delta}=\frac{\left\{R-\left[L_{2}+\pi_{L} \int_{\rho^{+}}^{1}\left(\rho H-L_{2}\right) d \rho\right]-c\right\}}{\left\{(1-\delta) R+\delta\left[L_{2}+\pi_{L} \int_{\rho^{+}}^{1}\left(\rho H-L_{2}\right) d \rho\right]-c\right\}^{2}}
$$

which is strictly positive because of $H<R$ in A5. Hence, the difference between the right hand side and the left hand side of $(*)$ is a strictly increasing function of $\delta$. For $\delta=0$, this difference is negative. Hence, there exists a critical value $\bar{\delta}$ where $(*)$ holds with equal- 
ity, and where for $\delta \leq \bar{\delta}$, (*) holds while for $\delta>\bar{\delta}$, it does not hold. One can calculate $\bar{\delta}$ from condition (*). Of course, if $\bar{\delta}>1$, investing at date 0 is never optimal. QED

Proof of Proposition 4: The entrepreneur can sell all the equity of the firm to an institutional investor for $(1-\delta) R+\delta\left\{L_{2}+\pi_{L} \int_{\rho^{+}}^{1}\left(\rho H-L_{2}\right) d \rho-c\right\}-I$. This is the amount that an institutional investor is bidding for $100 \%$ of the firm. Given that institutional investors behave competitively, each of them breaks even and bids exactly the gross profits of the firm minus the amount $I$ that they have to supply to finance the project and the investigation costs if the firm becomes distressed. Next we calculate the amount for which the entrepreneur could sell the equity to many small investors, provided that the Rich Investor invests all his wealth in the date 1 stock market. The small investors offer a price that makes them break even since they behave competitively. The shares are priced in a way that takes into account the equilibrium restructuring behavior of the Rich Investor. Hence, the entrepreneur's payoff is the firm's gross profits minus $I$ or:

(\#) $E=(1-\delta) R+\delta\left\{\left(1-\frac{\tilde{\mu}}{\delta x}\right) L_{2}+\frac{\tilde{\mu}}{\delta x}\left\{(1-\pi) L_{2}+\pi\left[\int_{0}^{\tilde{\rho}} L_{2} d \rho+\int_{\tilde{\rho}}^{1}[\lambda P+(1-\lambda) \rho H(\lambda)] d \rho\right\}-I\right.\right.$.

Notice that if the Rich Investor investigates a distressed firm and learns $\rho \geq \tilde{\rho}$, he buys a fraction $\lambda$

whether they will hold on to or sell their shares at date 1) will receive a payoff equal to the date 1 price of shares with probability $\rho H(\lambda)$ with probability $1-\lambda$. Recall that $\tilde{\mu}$ denotes the measure of firms that the Rich Investor investigates, given that he behaves optimally. The expression (\#) is strictly decreasing in $x$ if the Rich Investor cannot investigate all distressed firms (that is, $x>\frac{\tilde{\mu}}{\delta}$ ). The upper bound on the Rich Investor's wealth ensures that the Rich Investor cannot investigate all distressed firms (in the parameter region considered in this Proposition he will not investigate all distressed firms). If the Rich Investor could investigate all distressed firms, all firms without a date 0 blockholder would be investigated for sure. As a consequence, all firms would prefer to have no date 0 blockholder because of (***). As long as the Rich Investor will not investigate all distressed firms, the value of a firm having no date 0 
blockholder depends on the fraction of firms with initially dispersed ownership. Therefore,

$$
\text { if } \begin{array}{ll}
(1-\delta) R+\delta\left\{\left(1-\frac{\tilde{\mu}}{\delta x}\right) L_{2}+\frac{\tilde{\mu}}{\delta x}\left\{(1-\pi) L_{2}+\pi\left[\int_{0}^{\tilde{\rho}} L_{2} d \rho+\int_{\tilde{\rho}}^{1}[\lambda P+(1-\lambda) \rho H(\lambda)] d \rho\right\}\right\}-I\right. \\
\quad>(1-\delta) R+\delta\left\{L_{2}+\pi_{L} \int_{\rho^{+}}^{1}\left(\rho H-L_{2}\right) d \rho-c\right\}-I
\end{array}
$$

for $x=\frac{\tilde{\mu}}{\delta}$ (so that the Rich Investor investigates all distressed firms), as guaranteed by $(* * *)$, and the inequality is reversed for $x=1$, as guaranteed by $(* *)$, there exists an $x^{*}$ such that $\frac{\tilde{\mu}}{\delta}<x^{*}<1$ for which the left hand side of the above expression equals the right hand side. Hence, for $x=x^{*}=\frac{\tilde{\mu}}{\delta}\left\{\frac{\pi \int_{\tilde{\rho}}^{1}\left(\lambda P+(1-\lambda) \rho H(\lambda)-L_{2}\right) d \rho}{\pi_{L} \int_{\rho^{+}}^{1}\left(\rho H-L_{2}\right) d \rho-c}\right\}$, the equity value of a firm that has no date 0 blockholder is equal to the equity value of a firm with an institutional date 0 blockholder. Thus, if a measure $x^{*}$ of all firms issue shares to individual small investors and a measure $1-x^{*}$ issue shares only to one institutional investor each, all firms are indifferent between having a date 0 blockholder and not and no firm has an incentive to deviate. Note that the Rich Investor is willing to invest all his wealth in the date 1 stock market since (*) holds. QED

Proof of Proposition 5: If (*) holds, then the Rich Investor invests his wealth in buying blocks at date 1 from many small investors. If

$$
\begin{aligned}
& \left(1-\frac{\tilde{\mu}}{\delta}\right) L_{2}+\frac{\tilde{\mu}}{\delta}\left\{(1-\pi) L_{2}+\pi\left[\int_{0}^{\tilde{\rho}} L_{2} d \rho+\int_{\tilde{\rho}}^{1}[\lambda P+(1-\lambda) \rho H(\lambda)] d \rho\right]\right\} \geq \\
& L_{2}+\pi_{L} \int_{\rho^{+}}^{1}\left(\rho H-L_{2}\right) d \rho-c,
\end{aligned}
$$

then the equity value of firms that issue shares only to small investors at date 0 is higher than the equity value of firms that have an institutional date 0 blockholder even if all firms issue shares only to small investors so that the probability that a particular firm is investigated by the Rich Investor at date 1 is as low as possible, given that the Rich Investor invests all his wealth in date 1 blocks. Hence, no firm issues shares to a date 0 blockholder. If

$$
L_{2}+\pi_{L} \int_{\rho^{+}}^{1}\left(\rho H-L_{2}\right) d \rho-c>(1-\pi) L_{2}+\pi\left\{\int_{0}^{\tilde{\rho}} L_{2} d \rho+\int_{\tilde{\rho}}^{1}[\lambda P+(1-\lambda) \rho H(\lambda)] d \rho\right\},
$$


then the equity value of a firm that issues shares only to small investors is below the equity value of a firm with an institutional date 0 blockholder even if the probability of an investigation by the Rich Investor at date 1 is 1 . Hence, all firms prefer to have a date 0 blockholder. Clearly, the Rich Investor will invest all his wealth at date 0. QED

Proof of Proposition 6: If condition (*) does not hold, then the Rich Investor invests all his wealth at date 0 . Hence, firms obtaining funds from individual small investors will never be restructured. The equity value of a firm (or the price at which the entrepreneur can sell a firm) and hence the entrepreneur's payoff from selling a firm that obtains funds from individual small investors is $E_{S}=(1-\delta) R+\delta L_{2}-I$. The entrepreneur's payoff from selling a firm that obtains funds from an institutional investor is given by: $E_{I}=(1-\delta) R+\delta\left\{L_{2}+\pi_{L} \int_{\rho^{+}}^{1}\left(\rho H-L_{2}\right) d \rho\right\}-I-\delta c$. Clearly, $E_{I}>E_{S}$ because it was assumed that investigation pays, i.e., $\pi_{L}\left(\int_{\rho^{+}}^{1}\left(\rho H-L_{2}\right) d \rho\right)>c$. Hence, institutional investors bid higher than small investors would individually, and all firms have a date 0 blockholder. QED

Proof of Proposition 7: If (***) in Proposition 4 is not satisfied, all firms prefer to have a date 0 blockholder. Solving the condition that $(* * *)$ does not hold for $\pi_{L}$, one obtains the condition in the Proposition, $\pi_{L}>\frac{c+\pi\left(\int_{\tilde{\rho}}^{1}\left(\lambda P+(1-\lambda) \rho H(\lambda)-L_{2}\right) d \rho\right)}{\int_{\rho^{+}}^{1}\left(\rho H-L_{2}\right) d \rho} \equiv \tilde{\pi}_{L}$. If (*) holds, the Rich Investor prefers to invest his wealth in date 1 blocks. Then firms may want to have no date 0 blockholder. If moreover, conditions (**) and (***) are satisfied, firms with and without a date 0 blockholder coexist, as Proposition 4 has shown. The upper and lower bounds $\tilde{\pi}_{L}$ and $\bar{\pi}_{L}$ are calculated from condition (***) and (**) in Proposition 4, respectively. One obtains coexistence for 
$\tilde{\pi}_{L} \geq \pi_{L}>\frac{\left.c+\frac{\tilde{\mu}}{\delta} \pi\left\{\int_{\tilde{\rho}}^{1}\left[\lambda P+(1-\lambda) \rho H(\lambda)-L_{2}\right] d \rho\right]\right\}}{\int_{\rho^{+}}^{1}\left(\rho H-L_{2}\right) d \rho} \equiv \bar{\pi}_{L}$. Finally, if (*) is satisfied and in

addition $\pi_{L} \leq \bar{\pi}_{L}$ (that is, condition (**) is not satisfied), all firms prefer to have no date 0 blockholder. QED

Proof of Proposition 8: If $\delta \leq \hat{\delta}$, then $(* *)$ is not satisfied. Hence, no firm has a date 0 blockholder. (Notice that in $(* *)$ the left hand side is strictly decreasing in $\delta$ and the right hand side does not depend on $\delta$.) If $\hat{\delta}<\delta \leq \bar{\delta}$, the Rich Investor invests all his wealth in date 1 blocks because (*) in Proposition 3 is fulfilled (see Corollary 1 of Proposition 3 for the definition of $\bar{\delta}$ ). Moreover, $(* *)$ is satisfied and hence some firms obtain finance from institutional investors at date 0 . One can determine $x^{*}$ by solving

$$
\begin{aligned}
& (1-\delta) R-I+\delta\left\{\left(1-\frac{\tilde{\mu}}{\delta x}\right) L_{2}+\frac{\tilde{\mu}}{\delta x}\left\{(1-\pi) L_{2}+\pi\left[\int_{0}^{\tilde{\rho}} L_{2} d \rho+\int_{\tilde{\rho}}^{1}[\lambda P+(1-\lambda) \rho H(\lambda)] d \rho\right\}\right\}\right. \\
& \left.=(1-\delta) R-I+\delta\left\{L_{2}+\pi_{L} \int_{\rho^{+}}^{1}\left(\rho H-L_{2}\right) d \rho\right]-c\right\} .
\end{aligned}
$$

The left hand side of this equation gives the entrepreneur's date 0 payoff from selling the firm if its ownership is initially dispersed and the measure of firms with initially dispersed ownership is $x$. The right hand side of this equation gives the entrepreneur's date 0 payoff from selling the firm if it obtains funding from an institutional investor. The $x$ that equates left hand side and right hand side gives the measure of firms having no date 0 blockholder that makes firms indifferent between having and not having a date 0 blockholder. Solving the above equation for $x$, one obtains the expression $x^{*}=\frac{\tilde{\mu}}{\delta}\left\{\frac{\pi \int_{\tilde{\rho}}^{1}\left(\lambda P+(1-\lambda) \rho H(\lambda)-L_{2}\right) d \rho}{\pi_{L} \int_{\rho^{+}}^{1}\left(\rho H-L_{2}\right) d \rho-c}\right\}$. Clearly, $\frac{\partial x^{*}}{\partial \delta}<0$. Finally, if $\delta>\bar{\delta}$, (*) in Proposition 3 is not fulfilled and hence the Rich Investor invests all his wealth in date 0 blocks. Then, by Proposition 6, all firms have a date 0 blockholder. QED

Proof of Lemma 6: First we show that it is an equilibrium for the institutional investors and the Rich Investor to trade before either of them investigates the firms. The price at which there would be trade would be $P^{I I}=L_{2}+\pi_{L} \int_{\rho^{+}}^{1}\left(\rho H-L_{2}\right) d \rho-c$ due to the com- 
petition among the institutional investors. This was already argued in the proof of Lemma 4 (and will again briefly be shown in the proof of Lemma 7). If the institutional investor deviates from the proposed equilibrium by investigating, he could potentially increase his payoff by holding on to the firm if he learns $\rho H \geq P^{I I}$ and selling it at the price $P^{I I}$ if he does not learn $\rho$ or learns $\rho H<P^{I I}$. But the Rich Investor observes that the institutional investor has investigated the firm and understands that he will be willing to sell only the firms for which he has not learned $\rho$ or the firms with $\rho H \leq P^{I I}$. But then, trading at price $P^{I I}$ is not profitable for the Rich Investor. Hence, deviating to investigate the firm before selling it leads to no trade and hence does not make the institutional investor better off. Note also that the Rich Investor has no incentive to deviate from the proposed equilibrium. If he investigates the firm before trading, this is observed by the institutional investor. There will be no trade if the Rich Investor learns that $\rho<\rho^{+}$or if he does not learn $\rho$, in which case he will not restructure, by A4. There will also be no trade if the Rich Investor learns that $\rho \geq \rho^{+}$. The institutional investor understands that the Rich Investor will make an offer above $L_{2}$ only if $\rho \geq \rho^{+}$and that the offer will be not above the true value of the firm, given $\rho$. The institutional investor can get this true value by holding on to the firm and restructuring it. Hence, if the Rich Investor deviates by investigating the firm before trading, there is no trade and the Rich Investor makes less money than when he sticks to his equilibrium strategy of not investigating, in which case he makes a positive profit.

Now we have to show that there is no other equilibrium with trade. There are three other possibilities: (1) trade if the Rich Investor investigates before trading, but the institutional investors do not; (2) trade if the institutional investors investigate before trading, but the Rich Investor does not; and (3) trade if both the Rich Investor and the institutional investors investigate before trading. First consider case (1) in which the Rich Investor investigates but the institutional investors do not investigate before trading. This is not an equilibrium. The reasoning is the same as in the proof of Lemma 4 where it was shown that there was no equilibrium with trade in which the Rich Investor investigated before buying but the institutional investors did not. 
Case (2): Next consider the potential equilibrium in which the Rich Investor does not investigate before trading but the institutional investors do. The argument is the same as an argument already given in Lemma 4, as briefly follows. The Rich Investor will not make an offer above $L_{2}$. If the Rich Investor makes an offer at a particular price above $L_{2}$ (call it $P^{1}$ ), the institutional investor will accept only if he has learned that the true value of the firm is equal to or lower than the offer (including the case when he has learned that $\rho<\rho^{+}$), or if he has not learned $\rho$. If his offer was accepted, the Rich Investor loses on the overvalued accepted offers (for which the institutional investor learned $\rho$ ) and cannot gain on the firms for which the institutional investor did not learn $\rho$ (by A4) as a compensation for these losses. Note that trading at a price $L_{2}$ would protect the Rich Investor from losing money. Hence it could potentially be an equilibrium for the institutional investor to sell all firms for which he did not learn $\rho$ or for which he learned $\rho<\rho^{+}$to the Rich Investor at the price $L_{2}$. However, there are no gains from trade in this case. Hence there is no trade. The reason why there are no gains from trade is as follows: The institutional investor would not get a higher payoff than when holding on to the firms and not restructuring them. Moreover, the Rich Investor would not gain from trade either since the firms traded to him would be worth $L_{2}$ to him as well. This is obvious for the firms for which the institutional investor learned $\rho<\rho^{+}$. It is also true for the firms for which the institutional investor did not learn $\rho$. By assumption, then the Rich Investor cannot learn $\rho$ either if he attempts to do so.

Case (3): Finally consider the potential equilibrium in which both the Rich Investor and the institutional investors investigate the firms before trading. This is not an equilibrium. The reasoning is the same as the reasoning in the proof of Lemma 4 where it was shown that there was no equilibrium with trade in which both the rich Investor and the institutional investors investigated the firm before trading. QED

Proof of Lemma 7: The Rich Investor will buy the whole firm because of A5. He will buy it at a price that makes the institutional investor indifferent between holding on to the block and selling. If the institutional investor holds on to the block, his payoff is 
$L_{2}+\pi_{L} \int_{\rho^{+}}^{1}\left(\rho H-L_{2}\right) d \rho-c$. Hence, the price is set equal to this, i.e., $P^{I I}=L_{2}+\pi_{L} \int_{\rho^{+}}^{1}\left(\rho H-L_{2}\right) d \rho-c$. The Rich Investor has a payoff of $L_{2}+\pi \int_{\rho^{+}}^{1}\left(\rho H-L_{2}\right) d \rho-c$ (per measure 1 of firms) after taking over the firm, and hence, net of the purchase price $P^{I I}$, $L_{2}+\pi \int_{\rho^{+}}^{1}\left(\rho H-L_{2}\right) d \rho-L_{2}-\pi_{L} \int_{\rho^{+}}^{1}\left(\rho H-L_{2}\right) d \rho=\left(\pi-\pi_{L}\right)\left(\int_{\rho^{+}}^{1}\left(\rho H(1)-L_{2}\right) d \rho\right) . \quad$ QED

Proof of Proposition 9: If the Rich Investor invests at date 0, his profit per dollar invested is, according to Lemma 3, $\frac{1}{(1-\delta) R+\delta\left[L_{2}+\pi_{L} \int_{\rho^{+}}^{1}\left(\rho H-L_{2}\right) d \rho\right]} \delta\left(\pi-\pi_{L}\right) \int_{\rho^{+}}^{1}\left(\rho H(1)-L_{2}\right) d \rho$. If the Rich Investor buys blocks from institutional investors, he makes per dollar invested $\frac{1}{L_{2}+\pi_{L} \int_{\rho^{+}}^{1}\left(\rho H-L_{2}\right) d \rho}\left(\pi-\pi_{L}\right) \int_{\rho^{+}}^{1}\left(\rho H(1)-L_{2}\right) d \rho$ (see Lemma 7). The latter is strictly higher than the former. QED

Proof of Proposition 10: If the Rich Investor buys the date 1 block from many dispersed investors, his profits per dollar invested are $\frac{1}{\pi(1-\tilde{\rho}) P \lambda+c}\left(\pi \int_{\tilde{\rho}}^{1}(\rho H(\lambda)-P) \lambda d \rho-c\right)$, as was already calculated in Proposition 3. If the Rich Investor buys the firms at date 1 from institutional investors, then he makes $\left(\pi-\pi_{L}\right) \int_{\rho^{+}}^{l}\left(\rho H(l)-L_{2}\right) d \rho$ per firm, as was calculated in Lemma 7. He can buy a measure $\frac{W}{L_{2}+\pi_{L} \int_{\rho^{+}}^{1}\left(\rho H(1)-L_{2}\right) d \rho-c}$ of firms with his wealth (the price per firm that appears in the denominator was also calculated in Lemma 7). QED

Proof of Proposition 11: See the proofs of Propositions 4, 5, and 6. The only adjustment we need is substituting (****) for $(*)$. QED 
Proof of Proposition 12: See the proof of Proposition 7. The only adjustment we need is substituting (****) for (*). QED 


\section{Appendix B: Price Formation for Date 1 Shares With Liquidity Trading}

To complete the solution for the equilibrium, we need to analyze how the price, $P$, is formed in the date 1 stock market if the Rich Investor assembles a block by purchasing shares from many small investors. This section presents an example of a mechanism for the formation of the price of date 1 shares of firms that received bad news (referred to hereafter as "date 1 shares"). All assumptions made in Section II continue to hold. The basic point that Grossman and Hart's (1980) free-rider problem is alleviated by noise or liquidity trading was made by Kyle and Vila (1991). The model presented here is fairly standard and builds on Gorton and Pennacchi (1990). First, we extend the model of Section II to a general equilibrium model. Then, we solve for the price of date 1 shares.

\section{A. The Extended Model}

As above, the economy has entrepreneurs/firms, small investors, and a single Rich Investor. All agents are risk neutral. All investors have funds, no projects, but have a storage technology. For simplicity the interest rate in the economy is zero. At date $0 \mathrm{a}$ small investor may store his wealth or invest in a firm's project, either directly or via becoming a shareholder of an institutional investor. Each small investor's wealth $w$ is small relative to the size of an entrepreneur's project, $I$ : a positive measure of small investors who invest all their wealth is needed to finance a project.

We now specify that small investors will either be early consumers who derive utility from consumption at date 1 or late consumers who derive utility from consumption at date 2. All other agents derive utility from consumption at date 2 . More specifically, there is a double continuum of small investors in the space $[0,1]^{2}$, with measure 1 and each with wealth $w$. The wealth can be invested or stored for future consumption. At date 0 small investors do not know whether their preferences are for consumption at date 1 or date 2 . Just prior to date 1 , small investors learn their preferences. With probability $\lambda$ a small investor will derive utility only from consumption at date 1 , i.e., early consumption. With probability $1-\lambda$ a small investor will derive utility only from consumption at date 2 , i.e., late consumption. Early consumers will sell any securities they hold at date 1. If they have invested in a financial intermediary (an institutional investor), then they withdraw 
their funds at date 1 if they are early consumers. With probability $1-\pi$ late consumers receive another endowment at date 1 . This endowment is nonstorable. For simplicity, we assume this endowment is just enough to purchase a fraction $\lambda$ of the firms at date 1. Assuming that each small investor has the same portfolio, the above scenario is one in which fraction $\lambda$ of each firm's shares will be offered for sale at date 1 .

For the economy as a whole, we assume that the amount of available resources for investment from the small investors exceeds the funding requirements of the firms. When early consumers withdraw from the institutional investor, there is only a $1-\pi$ chance that the late consumers will have a new endowment to invest in the fund. If late consumers do not invest more in the fund, then the early consumers can be paid off by attracting new shareholders from the small agents who are storing their endowment but are indifferent between storage and investments in a fund. Finally, we assume that institutional investors stand ready to buy back existing shares, or issue new shares, at date 1 .

At date 1 the stock market opens. Agents trading in the stock market submit market orders to a competitive market maker that sets the price after observing the amount of buy and sell orders, but not the identity of traders. The market maker sets the price so that expected profits are zero.

There are potentially three kinds of traders in the stock market: early consumers who must sell any shares they hold to finance consumption at date 1; late consumers, who receive additional endowment with probability $1-\pi$, must buy shares since this new endowment is nonstorable; and finally, the Rich Investor who may buy shares. We assume that investors who are indifferent between trading and not trading do not trade.

\section{B. Discussion of the Assumptions}

The assumptions are clearly intended to be a simple way of generating uninformed "liquidity" buying and selling at date 1. Early consumers will sell measure $\lambda$ of each firm's shares. There are two types of potential buyers. Late consumers may arrive to buy shares. Or, the Rich Investor may arrive to buy shares. Since the Rich Investor may not be able to investigate every distressed firm and the late consumers do not always receive

\footnotetext{
${ }^{1}$ Otherwise, there could be excess demand that would affect the price and hence severely complicate the calculation of the price.
} 
an endowment, there is a chance that no buy orders arrive. If the Rich Investor does investigate, he learns the firm's prospects but does not buy the shares of low quality firms. In both cases, there are no buy orders and the price is set to $L_{2}$ since a firm that is never restructured is worth $L_{2}$. However, when the Rich Investor investigates, the chance he learns anything is perfectly negatively correlated with the late consumers' chance of receiving additional endowment at date 1. This assumption is purely to reduce the number or prices that we need to compute to exactly one price $P{ }^{2}$

\section{Price Formation in the Date 1 Stock Market}

To determine the Rich Investor's optimal trading strategy, we must determine the price at which he can buy date 1 shares. The price is set by the competitive market maker and is a function of the Rich Investor's equilibrium trading strategy, i.e., the quality of firms which the Rich Investor will buy, $\rho \geq \tilde{\rho}$, once he has investigated a measure of the distressed firms. Of course, if (*) (see Proposition 3) does not hold, the Rich Investor becomes a date 0 blockholder and the market maker sets a price of $L_{2}$.

\section{Proposition B1: (Date 1 Price Formation With Liquidity Trading) Suppose condition}

(*) holds. The equilibrium in the market for date 1 shares of distressed firms is characterized by:

$$
\begin{aligned}
& \text { (1) } P=\frac{\pi(1-\tilde{\rho}) \frac{\tilde{\mu}}{\delta x^{*}}}{\pi(1-\tilde{\rho}) \frac{\tilde{\mu}}{\delta x^{*}}+1-\pi} \int_{\tilde{\rho}}^{1} \rho H(\lambda) \frac{1}{1-\tilde{\rho}} d \rho+\left(1-\frac{\pi(1-\tilde{\rho}) \frac{\tilde{\mu}}{\delta x^{*}}}{\pi(1-\tilde{\rho}) \frac{\tilde{\mu}}{\delta x^{*}}+1-\pi}\right) L_{2} ; \\
& \text { (2) } \frac{\pi P \lambda}{\pi(1-\tilde{\rho}) P \lambda+c}\left(\pi \int_{\tilde{\rho}}^{1}(\rho H(\lambda)-P) d \rho-c\right)-\pi \tilde{\rho} H(\lambda)+\pi P(\tilde{\rho})=0,
\end{aligned}
$$
where $\tilde{\mu}=\frac{W}{\pi(1-\tilde{\rho}) P \lambda+c}$ and $x^{*}$ is the measure of firms issuing shares to many small investors in equilibrium (see Proposition 8).

\footnotetext{
${ }^{2}$ If there were situations in which the Rich Investor learned $\rho$ and wanted to buy a block in a firm and at the same time late consumers received a nonstorable additional endowment, we would have to calculate another price since now the marketmaker could receive two orders simultaneously.
} 
Proof: See Section D, below.

Clearly, $P \geq L_{2}$, which we assumed would be a feature of the equilibrium price in the main text. It is also apparent that $P>L_{2}$ if $\pi>0$ and hence there is some chance that the informed Rich Investor is a stock purchaser at date 1. This formalizes the idea that it is costly to acquire a position after bad news has arrived, news that indicates the need for restructuring. In this liquidity trading model, the price of date 1 shares partially reveals the value generation by the Rich Investor's monitoring activity. In contrast to Grossman and Hart (1980), the Rich Investor still has an incentive to monitor because he keeps some of the surplus generated by his monitoring activity because of the presence of liquidity traders. This is essentially the point made by Kyle and Vila (1991).

Now we can verify that in the important parameter regions, assumption A8 (which is of relevance only for the proof of Corollary 1 to Proposition 3) is fulfilled in the concrete price formation mechanism that we have demonstrated in this section.

Lemma B1: As long as (**) is satisfied, $\frac{\partial P}{\partial \delta}=0$ holds.

Proof: See Section D, below.

We have given only one example of price formation. There are other possible scenarios in which the date 1 share price is set such that the Rich Investor retains some incentive to monitor. But his incentive to monitor is reduced as compared to the case in which he does not have to share the surplus generated by his monitoring activity. One example would be a bargaining environment in which the Rich Investor and existing date 1 shareholders would split this surplus. The specifics of the price formation mechanism determine the extent to which the Rich Investor is able to benefit from his monitoring activity and hence his incentives to monitor. However, the results of this paper do not depend on the specifics of the price formation mechanism. Rather, it is required that the Grossman and Hart (1980) free-rider problem is not fully present. 


\section{Proofs}

Proof of Proposition B1: Equation (1) describes the price that yields zero expected profits for the market maker. Observing a buy order for a fraction $\lambda$ of shares, the market maker knows that this buy order could come from either late consumers or the Rich Investor. Late consumers receive an additional endowment with probability $1-\pi$. The Rich Investor becomes informed with probability $\pi$. He investigates a fraction $\frac{\tilde{\mu}}{\delta x^{*}}$ of all distressed firms and, if he learns $\rho$, acquires a block if and only if $\rho \geq \tilde{\rho}$. Hence, the conditional probability that the buy order comes from the Rich Investor is, using Bayes' Rule, $\frac{\pi(1-\tilde{\rho}) \frac{\tilde{\mu}}{\delta x^{*}}}{\pi(1-\tilde{\rho}) \frac{\tilde{\mu}}{\delta x^{*}}+1-\pi}$. If the buy order comes from the Rich Investor, the firm's expected value, given that the Rich Investor will restructure, is $\int_{\tilde{\rho}}^{1} \rho H(\lambda) \frac{1}{1-\tilde{\rho}} d \rho$. On the other hand, if the buy order comes from the late consumers, there will be no restructuring and hence the firm is worth $L_{2}$. Equation (2) stems from the first-order condition of the Rich Investor's problem (see Section III.C) ${ }^{3}$. QED

Proof of Lemma B1: As long as (**) is satisfied, not all firms will have an initially dispersed ownership (see Propositions 4 and 5). If firms with and without a date 0 blockholder coexist, $x^{*} \delta=\xi$ where $\xi$ does not depend on $\delta$, because $x^{*}=\frac{\tilde{\mu}}{\delta}\left\{\frac{\pi \int_{\tilde{\rho}}^{1}\left(\lambda P+(1-\lambda) \rho H(\lambda)-L_{2}\right) d \rho}{\pi_{L} \int_{\rho^{+}}^{1}\left(\rho H-L_{2}\right) d \rho-c}\right\}$ (see Proposition 8). Hence, $\frac{\partial P}{\partial \delta}=0$. Notice that if all firms have a date 0 blockholder $\left(x^{*}=0\right)$, the date 1 price is $L_{2}$ and hence does not depend on $\delta$ because the Rich Investor invests all his wealth at date 0 and hence nobody acquires a block at date 1 . QED

\footnotetext{
${ }^{3}$ Here it is assumed that the Rich Investor's problem is a quasiconcave program.
} 


\section{References}

Admati, Anat, Paul Pfleiderer, and Josef Zechner (1994), "Large Shareholder Activism, Risk Sharing, and Financial Markets Equilibrium," Journal of Political Economy, 102: $1097-1130$.

Aghion, Phillipe, and Patrick Bolton (1992), "An Incomplete Contract Approach to Bankruptcy and the Financial Structure of the Firm," Review of Economic Studies 59: 473494.

Akerlof, George A. (1970), “The Market For 'Lemons': Quality Uncertainty and the Market Mechanism," Quarterly Journal of Economics 84(3): 488-500.

Barclay, Michael and Clifford Holderness (1991), "Negotiated Block Trades and Corporate Control," Journal of Finance 41(3): 861-878.

Barclay, Michael and Clifford Holderness (1989), "Private Benefits From Control of Public Corporations," Journal of Financial Economics 25: 371-395.

Bethel, Jennifer, Julia Liebeskind, and Tim Opler (1998), "Block Share Purchases and Corporate Performance," Journal of Finance 53: 605-634.

Berle, Adolf A., and Gardiner C. Means (1932), The Modern Corporation and Private Property (New York: Macmillan).

Black, Bernard S. (1992a), "Agents Watching Agents: The Promise of Institutional Investor Voice," UCLA Law Review 39(4): 811-893.

Black, Bernard S. (1992b), "The Value of Institutional Investor Monitoring: The Empirical Evidence," UCLA Law Review 39(4): 895-939.

Black, Bernard S., and John C. Coffee, Jr.(1994), "Hail Britannia?: Institutional Investor Behavior Under Limited Regulation,” Michigan Law Review 92(7): 1997-2087.

Boehmer, Ekkehart (1998), "Business Groups, Bank Control, and Large Shareholders: An Analysis of German Takeovers," mimeo.

Bolton, Patrick, and Ernst-Ludwig von Thadden (1998), "Blocks, Liquidity, and Corporate Control," Journal of Finance 53(1): 1-25.

Boot, Arnoud W.A. (1992), "Why Hang On To Losers? Divestitures And Takeovers," Journal of Finance 47: 1401-1424. 
Brickley, James A., Ronald C. Lease, and Clifford W. Smith (1988), "Ownership Structure and Voting on Anti-takeover Amendments," Journal of Financial Economics 20 (1/2): 267-291.

Carleton, Willard T., James M. Nelson, and Michael S. Weisbach (1998), “The Influence of Institutions on Corporate Governance Through Private Negotiations: Evidence from TIAA-CREF," mimeo.

Chemmanur, Thomas, and Paolo Fulghieri (1994), "Reputation, Renegotiation, and the Choice Between Bank Loans and Publicly Traded Debt," Review of Financial Studies, 475-506.

Coffee, John C., Jr. (1991), "Liquidity versus Control: The Institutional Investor As Corporate Monitor,” Columbia Law Review 91: 1277-1368.

Demsetz, Harold (1983), "The Structure of Ownership and the Theory of the Firm," Journal of Law and Economics 16: 375-390.

Demsetz, Harold, and Kenneth Lehn (1985), “The Structure of Corporate Ownership: Causes and Consequences," Journal of Political Economy 93: 1155-1177.

Dewatripont, Mathias, and Jean Tirole (1994), "A Theory of Debt and Equity: Diversity of Securities and Manager-Shareholder Congruence," Quarterly Journal of Economics CIX: 1027-1054.

Diamond, Douglas (1984), "Financial Intermediation and Delegated Monitoring," Review of Economic Studies, 393-414.

Edwards, Jeremy and Klaus Fischer (1994), Banks, Finance and Investment in Germany (Cambridge University Press).

Feldman, M, and C. Gilles (1985), “An Expository Note on Individual Risk without Aggregate Uncertainty," Journal of Economic Theory 35: 26-32.

Franks, Julian and Colin Mayer (1998), "Ownership and Control of German Corporations," working paper.

Gorton, Gary and Frank Schmid (1998), "Universal Banking and the Performance of German Firms," working paper.

Gorton, Gary, and George Pennacchi (1990), "Financial Intermediation and Liquidity Creation," Journal of Finance 45(1): 49-71.

Grossman, Sanford, and Oliver Hart (1980), "Takeover Bids, the Free-Rider Problem, and the Theory of the Corporation," Bell Journal of Economics, 42-64. 
Grundfest, Joseph (1990), "Subordination of American Capital," Journal of Financial Economics 27 (1), September 1990, 89-110.

Holderness, Clifford G, and Dennis P. Sheehan (1985), "Raiders or Saviors? The Evidence on Six Controversial Investors," Journal of Financial Economics 14: 555-579.

Holderness, Clifford and Dennis Sheehan (1988), "The Role of Majority Shareholders in Publicly Held Corporations," Journal of Financial Economics 20, 317-346.

Holmstrom, Bengt, and Jean Tirole (1993), "Market Liquidity and Performance Monitoring," Journal of Political Economy 101: 678-709.

Hotchkiss, Edith S., and Robert M. Mooradian (1997), "Vulture Investors and the Market for Control of Distressed Firms," Journal of Financial Economics, vol. 43: 401-432.

Jensen, Michael C. (1986), "The Agency Costs of Free Cash Flow, Corporate Finance, and Takeovers," American Economic Review 76: 323-329.

Jensen, Michael C. (1989), "Eclipse of the Public Corporation," Harvard Business Review 67: 60-70.

Jensen, Michael C., and Richard S. Ruback (1983), "The Market for Corporate Control: The Scientific Evidence," Journal of Financial Economics 11(1-4): 5-50.

Judd, Kenneth L. (1985), "The Law of Large Numbers with a Continuum of IID Random Variables," Journal of Economic Theory 35: 19-25.

Kahn, Charles, and Andrew Winton (1998), "Ownership Structure, Speculation, and Shareholder Intervention,” Journal of Finance 53(1): 99-129.

Kyle, Albert S., and Jean-Luc Vila (1991), "Noise Trading and Takeovers," Rand Journal of Economics, 54-71.

La Porta, Rafael, Florencio Lopez-de-Silanes, and Andrei Shleifer (1999), "Corporate Ownership Around the World,” Journal of Finance 54(2): 471-517.

Maug, Ernst (1998), "Large Shareholders as Monitors: Is There a Trade-off between Liquidity and Control?," Journal of Finance 53(1): 65-98.

Shleifer, Andrei, and Robert W. Vishny (1986), "Large Shareholders and Corporate Control," Journal of Political Economy, 461-488.

Shleifer, Andrei, and Robert W. Vishny (1989), "Management Entrenchment: The Case of Manager-Specific Investments," Journal of Financial Economics 25: 123-139. 
Shleifer, Andrei, and Robert W. Vishny (1990), "The Takeover Wave of the 1980s," Science 249: 745-749.

Shleifer, Andrei, and Robert W. Vishny (1997), "A Survey of Corporate Governance," Journal of Finance 52: 737-783.

Weisbach, Michael (1994), "CEO Turnover and the Firm's Investment Decisions," Journal of Financial Economics 37: 159-188.

Zwiebel, Jeffrey (1995), "Block Investment and Partial Benefits of Corporate Control," Review of Economic Studies 62: 161-185. 
Figure 1: The Sequence of Events

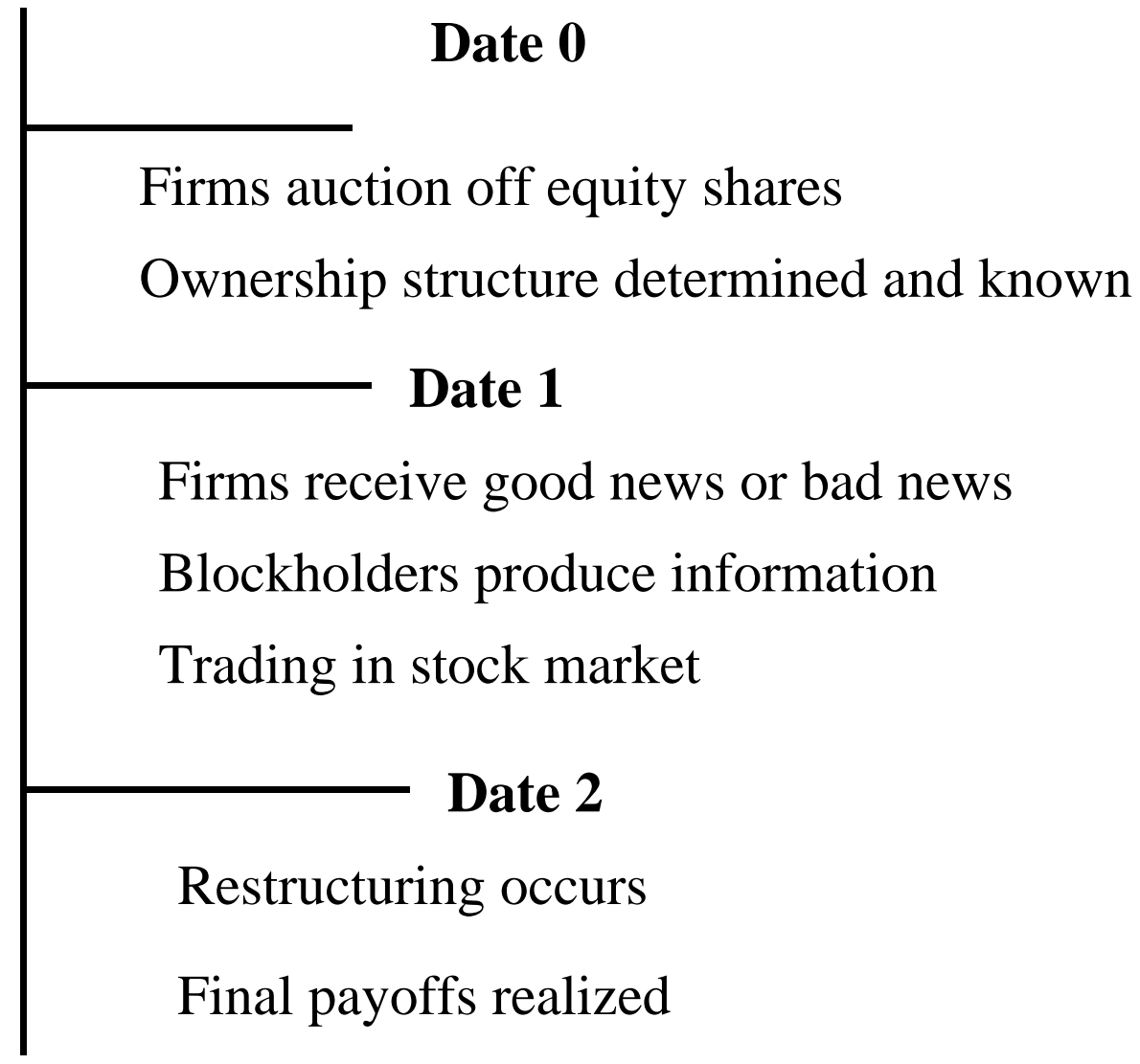


Figure 2: Coexistence of Firms With and Without Date 0 Blockholder

Equity

Value

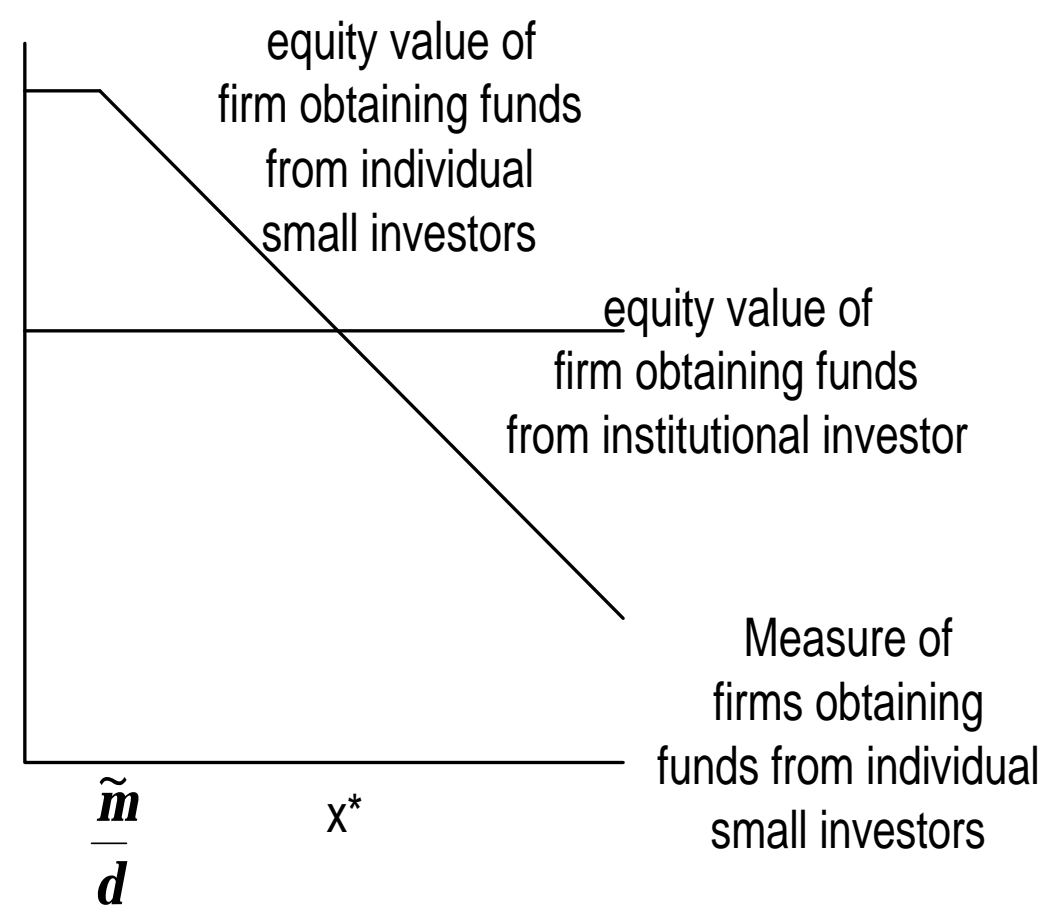

